\title{
Moving in the presence of others - a systematic review and meta-analysis on social facilitation
}

\author{
Edda van Meurs
}

\author{
Jona Greve \\ University of Münster, Germany
}

Bernd Strauss

This article has been accepted for publication in International Review of Sport \& Exercise Psychology, published by Taylor \& Francis. This is an original manuscript of an article published on August $1^{\text {st }}$, 2022, available online: https://www.tandfonline.com/doi/full/10.1080/1750984X.2022.2111663.

Social facilitation is an old research topic in psychology with diverse results: Performance in cognitive or motor tasks is either facilitated, inhibited or not affected, argued to be a function of task complexity. In his narrative review, Strauss, B. (2002. Social facilitation in motor tasks: A review of research and theory. Psychology of Sport and Exercise, 3(3), 237-256. https://doi.org/10.1016/S1469-0292(01)00019-X) found the presence of others to positively affect condition-based tasks (general drive hypothesis, Zajonc, R. B. (1965). Social facilitation. Science, 149(3681), 142-146. https://doi.org/10.1126/science.149.3681.269), and to negatively affect coordination-based tasks (capacity hypothesis, Manstead, A. S. R., \& Semin, G. R. (1980). Social facilitation effects: Mere enhancement of dominant responses? British Journal of Social and Clinical Psychology, 19(2), 119-135. https://doi.org/10.1111/j.2044-8260.1980.tb00937.x). This systematic review and meta-analysis focused exclusively on movement-based tasks, identifies the prevalence and magnitude of social facilitation, moderated by condition- and coordination-demands. Through forward searches (Scopus, PsycINFO, Web of Science, Academic Search Premier, ProQuest Dissertations, OvidSP) and backward searches, we identified $N=82$ human studies (7,008 participants) over 100 years. In the systematic review, condition-based tasks are generally facilitated, while results of coordination-based tasks performed under time and precision pressure differed (cf. Bond, C. F., \& Titus, L. J. (1983). Social facilitation: A meta-analysis of 241 studies. Psychological Bulletin, 94(2), 265-292. https://doi.org/10.1037/0033-2909.94.2.265). The meta-analytic moderator analysis of coordination- and condition-based tasks aligned with the systematic review. The experimenter's influential presence was emphasized. We support the capacity hypothesis and draw conclusions for the state of the theory and experimental limitations specific to social facilitation research.

Data, analysis code, $\&$ supplementary material: https://osf.io/tvk24/

Keywords: Social influence; social inhibition; experimenter presence; capacity hypothesis; coordination

Edda van Meurs, Jona Greve, \& Bernd Strauss, Department of Sport \& Exercise Psychology, University of Münster, Germany.

Version 2 of this pre-print includes more details on the history and development of social-facilitation theories than the published article (https://doi.org/10.1080/1750984X.2022.2111663). Throughout the peer-review process, additional (unpublished) studies have been included, which is why the results and analyses have changed slightly. The data and script are provided in this OSF: https://osf.io/tvk24/. Please cite this pre-print only with the authors' approval.

Correspondence concerning this article should be addressed to Edda van Meurs, Department of Sport \& Exercise Psychology, Horstmarer Landweg 62, 48149 Münster, Germany, Email: edda.vanmeurs@uni-muenster.de

The authors would like to thank Lena Kober for her time-intensive and meticulous work on the data acquisition for this article. This study was conducted without external funding.
'Social Facilitation' goes back to Allport (1920, 1924) and describes 'an increase in response merely from the sight or sound of others making the same movement' (Allport, 1924, p. 262). The term goes hand in hand with Robert Zajonc, who published the highly influential paper "Social Facilitation" in "Science" in 1965. In this seminal review, Zajonc (1965) summarized more than 60 years of research that referred directly (or indirectly, before 1924) to social facilitation in humans as well as in animals (e.g., dogs, chickens, cockroaches, monkeys). Zajonc was the first to identify a consistency in the until then very diverse findings that ranged from inhibited to facilitated performances: welllearned responses were facilitated and newly acquired responses inhibited. This breakthrough was followed by research "directly testing his position, elaborating upon it, or suggesting alternatives" (Geen \& Gange, 1977, p. 1268). Social facilitation studies following this 
school have examined whether and how a person's performance is impacted when others are (a) merely present (Allport, 1924), or (b) co-acting with the performer (Gates, 1924). According to Allport's definition, social facilitation does not cover all possible effects of the presence of an observer on a performer (cf., competition, rivalry, cheering, booing or other behaviors), and can be considered as the minimal experimental paradigm of social presence. It is there different to social influence (Latané, 1981; see e.g., Park et al., 2022) and focuses on the impact on performance rather than for example attentional or shared experiences in social presence (cf., Steinmetz \& Pfattheicher, 2017).

The start of social facilitation research has often been dated at the end of the $19^{\text {th }}$ century (Féré, 1887; Triplett, 1898). Triplett's (1898) archival pace-maker analysis and subsequent so-called "competition machine" experiment with children were the first to distinguish between the diverging effects of (a) a desire to win, (b) rivalry or competition, and (c) the sight and sound of another person who performs the same movement. However, more recently, criticism regarding the experimental task, the results and the importance to the field of social psychology has been raised (Martin, 2020; Stroebe, 2012). After differentiating social facilitation from competition effects, more attention was given to the underlying mechanisms for facilitated and inhibited performances.

\section{Theories of social facilitation}

Theories of social facilitation have been developed predominantly between 1965 and 1985. At the heart of most theories is the generalized drive hypothesis proposed by Zajonc (1965; Figure 1A). On the basis of the Hull-Spence Behavior Theory (Hull, 1943; Spence, 1956), he suggested that the presence of others from the same species (both true for humans and animals) affects the subject's generalized, non-directive drive, which in turn increases the probability of executing the dominant reaction to the task. A drive state is the increased arousal and motivation to reach a certain goal by choosing the behavior that most effectively meets the requirements, i.e., the dominant reaction (Spence, 1956). Tasks are simple and well-learned when the dominant reaction is correct, whereas complex or unknown tasks do not have a dominant reaction yet. Hence, if the dominant reaction is enforced, an easy task is assumed to be facilitated. Consensus was - to a degree - reached that the presence of others impacts the state of activation of the performing subject, resulting in an increase of the dominant response. However, the mediating conditions as to why drive increases, constitute the main differences between the theoretical frameworks. Cottrell $(1968,1972)$ and Henchy and Glass (1968) proposed a model, claimed to be valid only in humans, that - supposedly - opposed the generalized drive hypothesis by suggesting that social facilitation is learned from socialization and that a possible evaluation would have an energizing effect (Figure 1B). Subsequently, Guerin and Innes (1982) proposed the social monitoring theory (Figure 1C), where drive increases from the anticipated threat/unpredictable behavior of others. This potential mediation was picked up by Blascovich and colleagues (1999): In the biopsychosocial model, challenge and threat are motivational states that arise from the increased appraisal demand (e.g., presence of a spectator). Threat is experienced when one believes their personal resources to be insufficient to meet the unknown demands, hence, situational novelty is hypothesized to increase threat (Blascovich et al., 1993) and to consequently trigger physiological fight-or-flight responses.

After several years of experimental testing, no final proclamation regarding the importance of evaluation apprehension could be made: Zajonc (1980) found mere presence to be sufficient for a change in the subjects' level of drive, while Sanders (1981) concluded that the mere presence explanation was the least applicable of all theories. By 1982, the mere presence hypothesis could not reliably be accepted nor rejected (Guerin, 1993; Guerin \& Innes, 1982). Consequently, scientists suggested other cognitive, motivational and affective mechanisms to explain social facilitation in the early 1980's. The distracting potential of others and subsequent attention-capacity restrictions resulted in a new branch of theories (Figure 2A). In five experiments on the capacity hypothesis, Manstead and Semin (1980) identified that the direction of the social facilitation effect was moderated by the cognitive demands of the task, a different operationalization of task difficulty. If observers tax the attentional capacity, then the performance of complex tasks should be impaired, whereas the automatic processing during simple tasks is unhindered in case of limited attentional capacities (Shiffrin \& Schneider, 1977). This was further developed by Baron (1986, overload hypothesis, Figure 2B) and Sanders (1981, distraction-conflict hypothesis, Figure 2C). These branches of theories have been looked at as mutually exclusive, however, e.g., Strauss (2002) has suggested an integrated framework based on different task demands. 


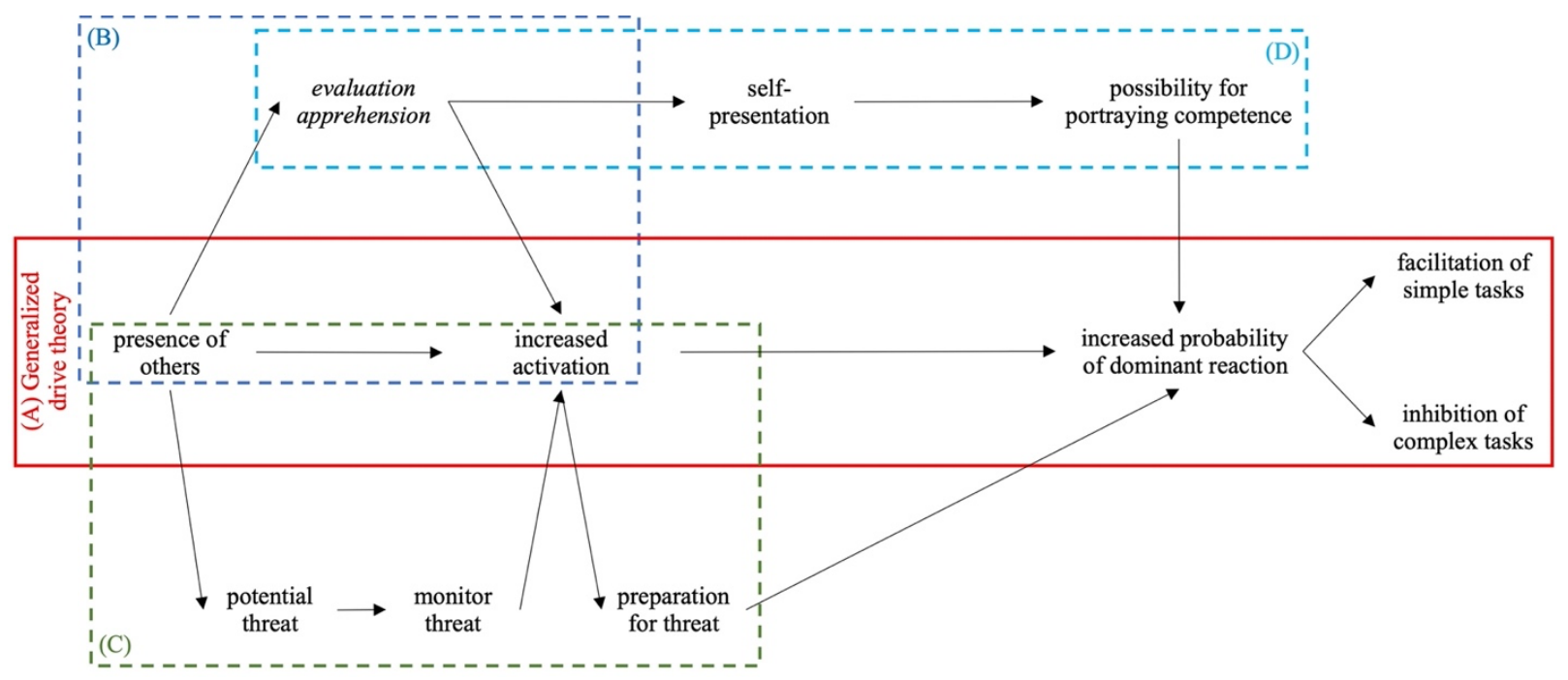

Figure 1. Activation-based theories. (A) Generlized drive theory (Zajonc, 1965); (B) evaluation-apprehension hypothesis (Cottrell, 1968; Henchy \& Glass, 1968); (C) monitoring hypothesis (Guerin \& Innes, 1982); (D) cognitive-motivational model (Paulus, 1983).

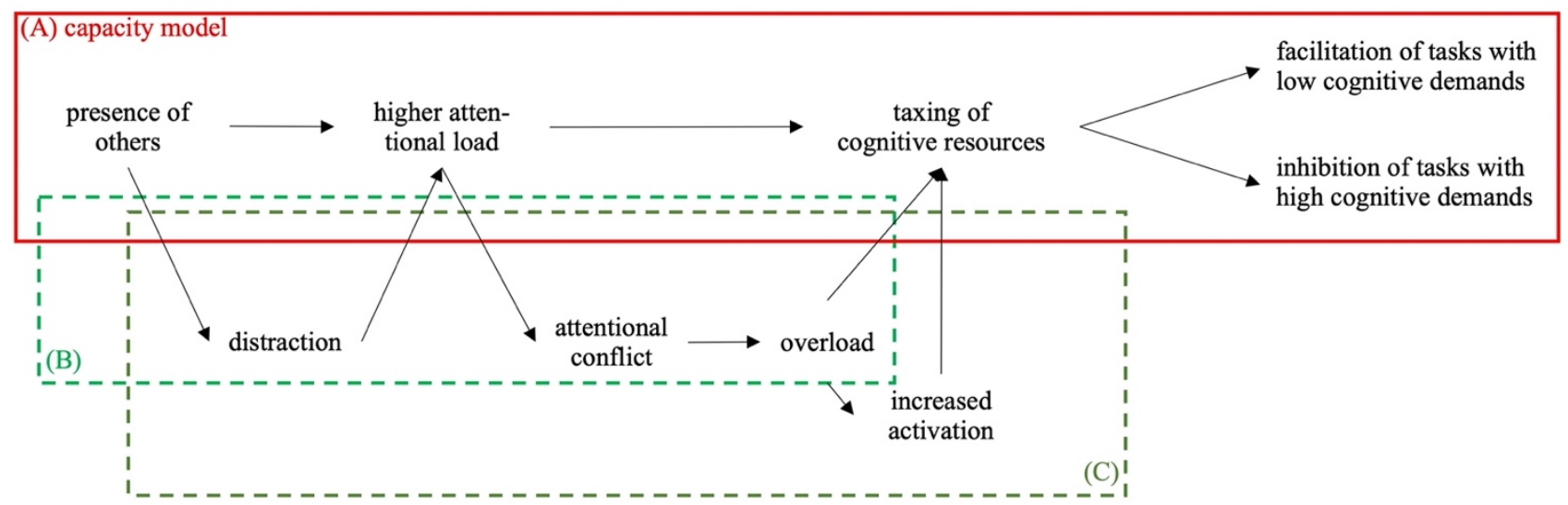

Figure 2. Attention-based theories. (A) Capacity model (Manstead \& Semin, 1980); (B) overload hypothesis (Baron, 1986); (C) distraction-conflict hypothesis (Sanders, 1981).

\section{Empirical evidence on social facilitation}

The influence of a member of the same species has been researched both in humans and non-human animals (see e.g., Zajonc et al., 1969). Until Dashiell (1930), every increase in behavior in the presence of other humans was coined as social facilitation (Guerin, 1993). Later, these were distinguished as social learning, imitation or social loafing (Clayton, 1978). Throughout the theoretical discussions between 1965 and 1982, animal studies became more popular: if mere presence effects can be found in non-human populations, evaluation apprehension or other cognitive theories are incomplete (cf. Guerin, 1993).
The majority of tasks used in human experiments are cognitive tasks (e.g., pseudo recognition, list learning, word association; see Geen \& Gange, 1977; Guerin, 1993), but also motor tasks (e.g., Pursuit Rotor Task, finger maze, balancing, rowing; see Landers \& McCullagh, 1976; Oviatt \& Iso-Ahola, 2008; Strauss, 2002). The most common experimental social facilitation paradigm constitutes a 2 (alone vs spectator/co-actor) $\mathrm{x} 2$ (simple vs complex task) design. A classic example is the study by Miyamoto (1979), who asked students to complete either a simple finger-maze task (only 12 cul-de-sacs) or a complex finger-maze task (24 cul-de-sacs). Half of the participants completed the maze alone, while the other half was carefully observed 
by another student. These types of research designs are sometimes accompanied by manipulation of the evaluative potential held by the other person(s), by their behavior (working on another task/blindfolded vs watching the subject intently), the instructions by the experimenter (e.g., "[This student] will be sitting here watching and evaluating your performance", Groff et al., 1983, p. 364) or their expertise at the task (novice vs expert). To test for potential attentional explanations, researchers compared performing alone or in front of a human audience to the effect of distracting non-social or self-attention stimuli (mirror, mannequin; e.g., Rajecki et al., 1977).

Several reviews between 1965 and 1985 do not align to support one theory. In the first comprehensive review, Geen and Gange (1977) concluded that the generalized drive theory (Zajonc, 1965) was the most parsimonious theory after 12 years of research. According to the authors, social facilitation appears to result from "emotional arousal" (p. 1283). Furthermore, evaluation apprehension was found to elicit both the hypothesized responses as well as the opposite: no difference between high-evaluation and low-evaluation conditions. Overall, however, Geen and Gange (1977) described it as an "immediate antecedent of socially induced drive" (p. 1268), but not a necessity. This distinction had not been made in the original paper in 1965, but after the increasing discussion around the anticipation of positive and negative consequences, Zajonc (1980) clarified that the audience need not engage in any sort of behavior to facilitate or inhibit performance.

The renowned meta-analysis by Bond and Titus (1983) systematically summarized 241 studies on human social facilitation, encompassing both cognitive and motor tasks in the presence of audiences or co-actors. Until 1982, a total of $N=23,970$ subjects had been investigated. The overall social facilitation effect was found to be small, explaining only $3.1 \%$ of the variance in complex and $0.3 \%$ in simple tasks. In addition, the authors categorized effects by the dependent measure (physiology, performance quantity/speed, performance quality/accuracy, miscellaneous). They confirmed one of the prevailing assumptions: in the presence of others, subjects perform complex tasks less accurately or more slowly and experience higher arousal, while simple tasks are executed more quickly. The social facilitation during simple tasks was more prominent in measures of speed as compared to measures of accuracy (cf. Bond \& Titus, 1983, p. 273). This was more recently

\footnotetext{
${ }^{1}$ Despite similar ideas, the models by Fleishman (1957) and Bös (2017) classify balancing and gross-motor coordination differently,
}

confirmed in an experiment with rats who had to run (speed-task) and pull a lever (accuracy-task) while in the presence of another rat or alone (Sekiguchi \& Hata, 2019b). Speed improved while accuracy decreased in the mere presence of a conspecific.

The seminal book "Social Facilitation" by Guerin (1993, $1^{\text {st }}$ edition) provides a unique in-depth review of the entirety of the highly diverse social facilitation research. Here, Guerin (1993) distinguished between studies investigating the effects of mere presence, of the experimenter, or of a passive or active observer. He summarized that social facilitation appears to be possible without evaluation or social conformity. In a metaanalysis of 11 studies, Uziel (2007) additionally identified a difference in expecting positive or negative consequences and thereby experiencing an increase in enthusiasm or anxiety, respectively. A positive orientation (reflecting extraversion) helped improve performance in the presence of others, while a negative orientation (reflecting neuroticism) led to impairment.

\section{Social facilitation during motor tasks}

Special attention in the field of social facilitation has been given to contexts in which a motor response is required (see already Moede, 1920). Movement or physical activity are all motor tasks primarily aimed at, and relying on, the activation of skeletal muscles (Welk, 1999). Several hierarchical taxonomies of motor skills/abilities have been proposed (see e.g., Fleishman, 1957; Lämmle et al., 2010; Newell, 2020). Fleishman (1957) split these motor abilities into (1) physical-proficiency abilities (strength, speed, endurance, flexibility, balance, gross-motor coordination), which predominantly require energy, and (2) perceptual-motor abilities (e.g., control precision, reaction time and accuracy, manual and finger dexterity), which predominantly require efficient and accurate information processing and translation. Similarly, the model of motor abilities by Bös (1987; see Lämmle et al., 2010; cf. Utesch et al., 2019) differentiates motor tasks based on their condition-oriented (energy-/effort-based) abilities (e.g., strength, endurance, speed) and coordination-oriented (information-based) abilities (e.g., coordination under time pressure, coordination under precision pressure, also referred to as skill-based; see Figure 3$)^{1}$. Perceptual-motor tasks are characterized by a higher cognitive load. These tend to be considered more complex in nature. Tasks with high demands on energetic processes

emphasizing their ambiguous character. However, a complete comparison of both approaches exceeds the scope of this article and is not the aim of this investigation. 


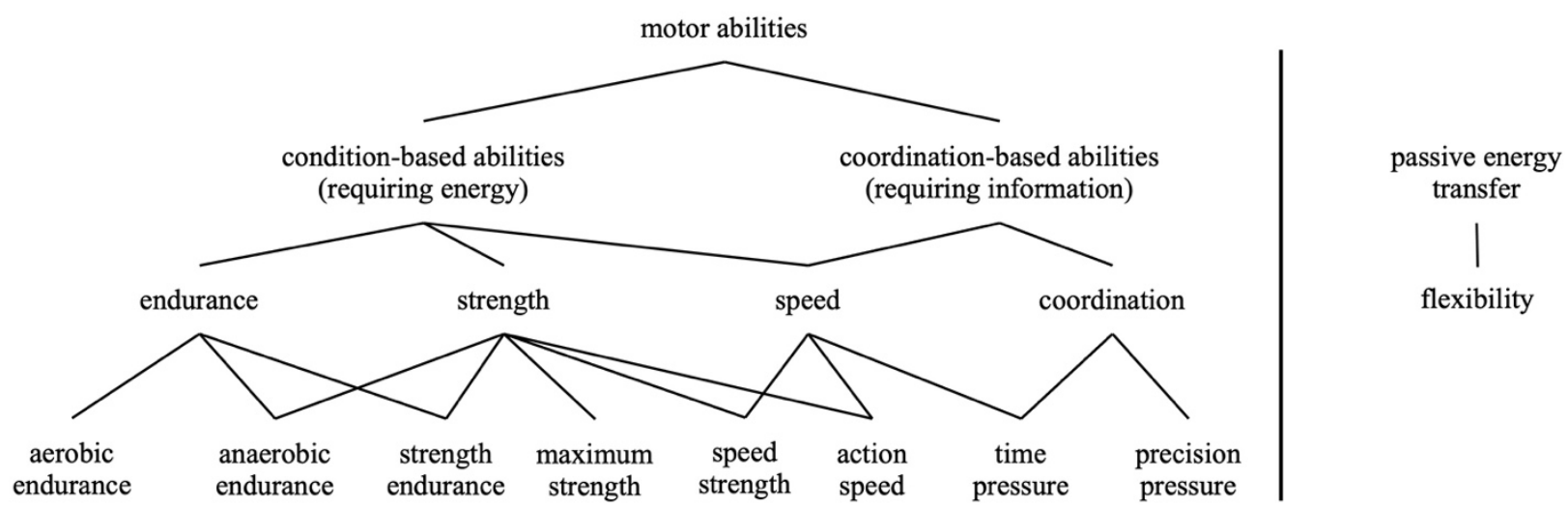

Figure 3. Model of motor abilities (derived from Bös, 1987).

or condition (relying on physical-proficiency abilities), on the other hand, require little learning (but rather continuous extensive exercising) and are considered simple.

Some movements, especially during sports games, require more than one motor ability and cannot be classified as either physically or perceptually dominant. This often leads to the necessity to handle a speed-accuracy trade-off (Fitts \& Posner, 1967), depending on the task requirements (Schmidt \& Wrisberg, 2000, p. 156). Motor tasks that do not have a heavy reliance on either coordination or condition will in the following be considered as "mixed tasks" (Strauss, 2002).

The effects of social presence on motor task performances vary from (mostly marginal) improvements to no difference to substantial decrements (Landers \& McCullagh, 1976; Strauss, 2002). In the first comprehensive summary of empirical evidence on motor tasks, Daniel Landers and McCullagh (1976) summarized 84 studies, highlighting that speed of performance (referred to as "quantitative aspects", cf. p. 130) appear to be facilitated by (competitive) co-action, whereas accuracy (referred to as "qualitative aspects") remained unaffected or the operationalization was poorly executed, invalidating the findings. Co-action effects were most pronounced in discrete or serial tasks (with an identifiable endpoint; Fitts \& Posner, 1967), as opposed to continuous tasks (e.g., Pursuit Rotor Tracking). Daniel Landers and McCullagh (1976) also contended that in most studies, the passive audience or co-actor was influential enough to elicit an inhibition of the correct response during a novel task. Accuracy performance during well-learned tasks, however, seems to increase significantly in several experiments.

Oviatt and Iso-Ahola (2008), synthesized research on any social-presence effect (mere presence, co-action, evaluation, social loafing, choking) during motor tasks from 1982 to 2004, running separate meta-analyses for each type of social influence. They found a very small overall mere presence effect in 18 studies. When controlling for the type of task, performance appeared to be facilitated in laboratory tasks $(\mathrm{ES}=0.65)$, while sports- or exercise-related tasks remained unaffected $(\mathrm{ES}=-0.12)$. However, the distinction between sports- and laboratory tasks is not stated clearly does not align with previous definitions (cf. e.g., Strauss, 2002).

Strauss (2002) approached the distinction of speed and accuracy outcomes differently. Rather than comparing speed- and accuracy-dependent motor tasks, he hypothesized parallels between the model of motor abilities by Bös (1987; Figure 3), the general drive hypothesis (Zajonc, 1965) for condition tasks, and the $c a-$ pacity hypothesis by Manstead and Semin (1980; Figure 2) for coordination tasks. Joining the motor and social facilitation models, motor tasks with high cognitive demands (i.e., information-based/coordination) should be inhibited, while motor tasks with low cognitive demands (i.e., energy-based/condition) should be facilitated. Based on Bond and Titus (1983) and Landers and McCullagh (1976), time and precision pressure as the subcategories of coordination-based tasks should be affected differently. He thereby expanded on the idea already proposed in Moede's seminal book in 1920 (see e.g., Danziger, 2000) that energy-based tasks appear to be facilitated, in contrast to cognitively determined tasks. These effects can be further sub-categorized into coordination-based tasks performed under time pressure ("as quickly as possible") or under precision pressure ("as accurately as possible"). In Strauss' (2002) narrative summary, coordination-based tasks were either facilitated when well-learned (Landers et al., 1978; Martens, 1969b), remained unaffected by the presence of others (Wankel, 1972), or were inhibited (Martens, 1969a), especially when apprehending evaluation 
(Haas \& Roberts, 1975). Tasks requiring endurance and some forms of strength were commonly facilitated (Beckmann \& Strang, 1992; Strube et al., 1981; Worringham \& Messick, 1983). No conclusive statement could be made regarding exercises with mixed requirements (e.g., tennis). This may be due to the speedaccuracy trade-off: task performances are a composite of both requirements, and the trade-off could cancel out potential effects.

Is this observation true across all motor tasks performed in the presence of others? Oviatt and Iso-Ahola (2008) studied several social-influence phenomena, however, they did not distinguish between the different motor task types on account of the task demands (Bond \& Titus, 1983; Strauss, 2002). To our knowledge, social facilitation research mostly looks at cognitive performance (see Guerin, 1993), but the peer-reviewed evidence on social facilitation (mere presence and co-acting) on motor tasks has not been reviewed systematically. A few literature syntheses published as papers or in books (Burnham, 1910; Guerin, 1993), reviews (Hollingworth, 1935; Zajonc, 1965) or meta-analyses (Bond \& Titus, 1983; Uziel, 2007) addressed cognitive tests as well as motor tasks, while previous narrative reviews by Strauss (2002) and Daniel Landers and McCullagh (1976) focused on social facilitation during motor tasks. We conducted a joined systematic review as well as a subsequent meta-analysis to expand on the motor-task related findings by Bond and Titus (1983) as well as to test the hypotheses proposed by Strauss (2002). It is thereby the first systematic qualitative and quantitative summary of social facilitation during motor tasks to cover the entirety of research since Triplett (1898), distinguishing between condition and coordination demands on the one hand and, within coordination, between accuracy-reliant and speed-reliant tasks on the other hand. We aim to quantify the magnitude and direction of the social facilitation effect under certain requirements and discuss how the available (cognitive) theories generalize to the field of sports and movement performances. Methods

The review and meta-analysis follow the guidelines from the Preferred Reporting Items for Systematic Reviews and Meta-Analyses Statement (Moher et al., 2009; Shamseer et al., 2015) and was updated using the 2020 guidelines (Page et al., 2021).

\footnotetext{
${ }^{2}$ We thank the reviewers for their recommendation to exclude possible biases and to avoid overlooking strong unpublished studies that should be included. Finally, we added 7,260 additional studies to the screening.

International Review of Sport \& Exercise Psychology
}

The literature search was conducted on December $6^{\text {th }}, 2019$, by systematically searching multiple electronic search engines based on the definitions by Allport (1924) and Zajonc (1965): Scopus, PsycINFO, Web of Science and Academic Search Premier. For unpublished work, the databases ProQuest Dissertations and OvidSP were searched on February $8^{\text {th }}, 2022$, while limited to the original date. ${ }^{2}$ Databases were scanned for "social facilitation", coaction, co-action, "mere presence" or audience, crossed with "motor task", athletic, sport, physical, exercise or movement (for the search strategy per database, see Supplement 1). Backward searches of the meta-analysis by Bond and Titus (1983), the reviews on social facilitation during motor performances by Daniel Landers and McCullagh (1976) and Strauss (2002), and the unpublished master's thesis (review and meta-analysis on social facilitation, choking under pressure and home advantage) by Oviatt $(2005)^{3}$ were conducted on December $11^{\text {th }}$, 2019.

Screening was conducted using the web software Rayyan (Ouzzani et al., 2016). Two reviewers completed the screening of the titles and abstracts independently. Disagreements were discussed and resolved by consensus or by third-party arbitration.

\section{Eligibility criteria}

Studies were included into the qualitative review if they met the following criteria:

a) The article examined social facilitation during a movement task;

b) The experimental design had at least one alone and one social presence condition;

c) Analyses were conducted with original empirical data;

d) Subjects were limited to humans;

To compute the meta-analytic effect, one criterion was added:

e) The article provided sufficient information to compute effect sizes.

Studies could assess any age range or level of participation but were excluded if they investigated animals or if the tasks were primarily cognitive or included competition. We did not reach out to known authors for additional unpublished studies, since this would only have been possible for half of the considered research

\footnotetext{
3 This unpublished master's thesis (retrievable under https://www.proquest.com/docview/304997041?) was in parts published (without data on e.g., home advantage or choking literature) as a book chapter (Oviatt \& Iso-Ahola, 2008).
} 
period and known authors. Articles without original data, i.e., reviews, meta-analyses or book chapters were not considered. The results of each step are presented in Figure 4. All articles that met the inclusion criteria are listed in Supplement 3-5.

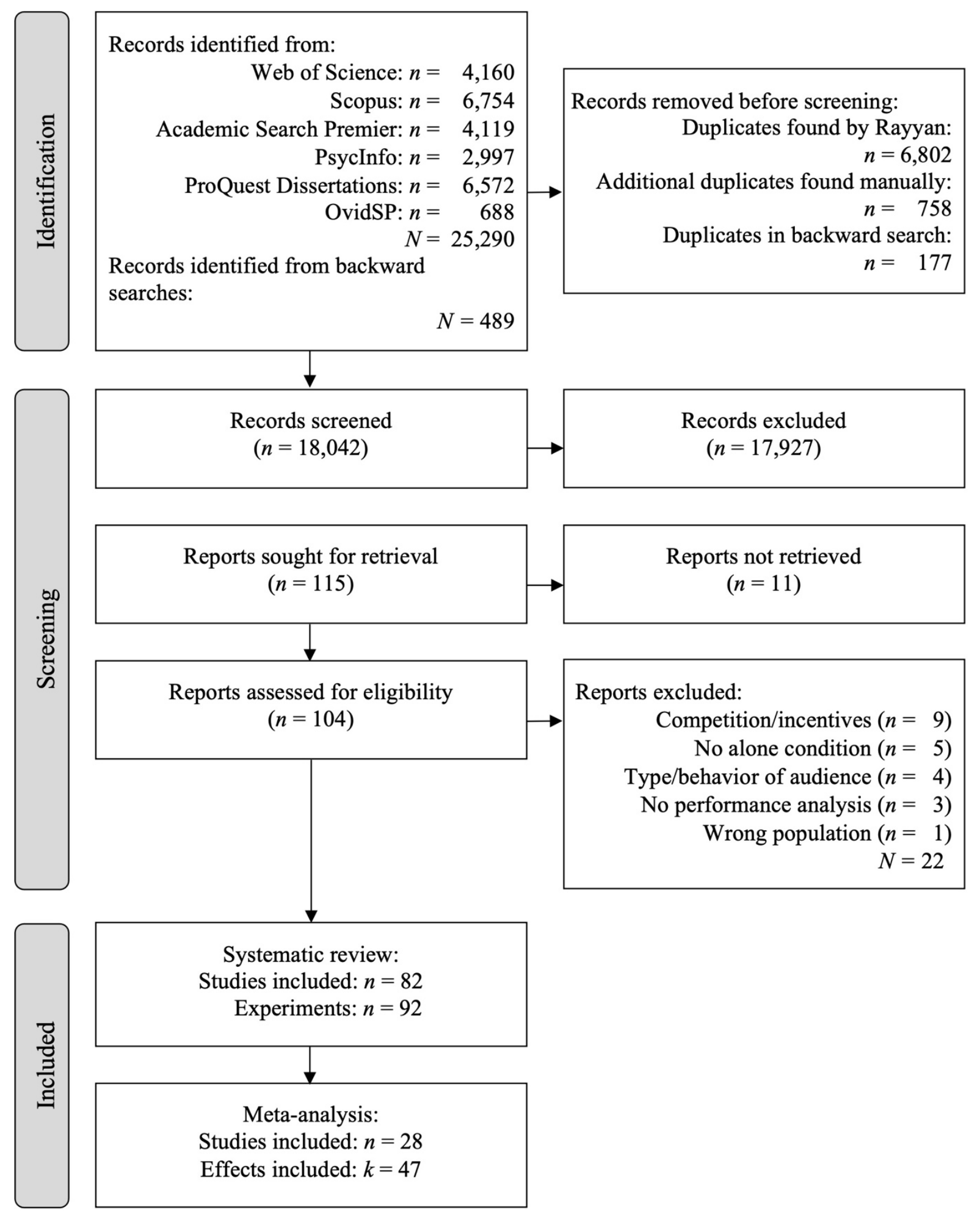

Figure 4. PRISMA 2020 flow chart. 


\section{Quality assessment and information coding}

The quality of each experiment, i.e., their internal validity was assessed by two independent judges blind to the aim of the systematic review. They followed the eight criteria determined by the authors, alluding to the Quality Assessment of Controlled Intervention Studies (NHLBI, 2020; Supplement 2). Criteria were either evaluated as (a) met, (b) not met, (c) could not be determined, or (d) not reported. Disagreements were checked and resolved by third-party arbitration.

Characteristics and variables of each study were extracted from the articles by one researcher and confirmed afterwards by a second, guided by the Cochrane Handbook for Systematic Reviews (Higgins \& Green, 2011). The selection of attributes followed Bond and Titus (1983). To characterize each experiment, we coded information relating to (a) the article's characteristics (metrics, publication year), (b) the quality assessment (quality criteria, experimenter's presence), (c) the sample's characteristics (age, sex distribution, subject's level of anxiety, initial skill level of the subject), (d) the task's characteristics (qualitative or quantitative performance assessment, task difficulty, task familiarity, movement categorization: coordination under precision pressure, coordination under time pressure, endurance, strength, speed, cf. Bös et al., 2015, measure), and (e) the audience's characteristics (number of others, sex distribution, role \& status of others, familiarity of others, evaluative potential). Whenever no or insufficient details were provided, it was recorded as "not reported" (nr).

\section{Statistical analysis}

The protocol, data, scripts, and supplementary analyses are available on the Open Science Framework: https://osf.io/tvk24. All analyses were conducted using RStudio (R Core Team, 2019, version 3.6.0) and the Hands-On Guide by Harrer et al. (2019b). Agreement of inclusion and quality assessment was calculated using the irr-package (Gamer et al., 2019). The metaanalysis was conducted using several R-packages: meta (Balduzzi et al., 2019), metafor (Viechtbauer, 2010) and dmetar (Harrer et al., 2019a). Standardized mean differences between the alone and the social facilitation conditions (Hedges \& Olkin, 1985) were calculated from sub-sample sizes, means and standard deviations or main-effect analyses (e.g., $F$ - or $t$-statistics, adjusted error term when hierarchical/factorial design, cf. B. T. Johnson \& Eagly, 2014). If several social facilitation conditions in line with the theories were analyzed, they were treated as separate tests and the sample size of the alone condition was divided by the number of conditions (recommended by Higgins \& Green, 2011). The non-theoretically backed conditions (e.g., gender-conditions) were collapsed (see Becker, 1988; Higgins \& Green, 2011). In case of additional manipulations (e.g., a competitive condition, cf. White, 1991), only the theoretically justified comparison was included.

To calculate effect sizes for repeated-measures designs, correlations between measurements or the pretest $S D$ are required (cf. Morris \& DeShon, 2002). Cohen's $d$ was calculated by dividing the $t$-value by $\sqrt{n}$ (B. T. Johnson \& Eagly, 2014). The sampling variance was derived following Becker (2009, described in Koenig et al., 2011). Whenever more than one dependent variable was assessed (e.g., Miyamoto, 1979; Pessin \& Husband, 1933: \# of trials and error rate; Martens, 1969a: arithmetic error and intra-variance of error; Bowman \& Dunn, 1982; El Baden, 1984: multiple measures of fitness), each outcome was considered as an individual effect. Measures of learning (e.g., number of trials until criterion) were excluded to focus primarily on performance rather than learning. The effect of audience or co-actor presence on learning is discussed in the systematic review.

The dependent variables were either measures of skill (e.g., time on target, number of sit-ups) or measures of failure (e.g., number of errors). Accordingly, all effect sizes were transformed to provide a meaningful standardized mean difference $d$ (esc-package, Lüdecke, 2019) between the alone-conditions and the (pooled) social facilitation conditions. A negative effect indicates an inhibition of performance (i.e., a decrease in a measure of skill in the presence of an audience or co-actor, or an increase in a measure of failure), whereas a positive effect indicates a facilitation (i.e., an increase in a measure of skill in the presence of an audience or co-actor, or a decrease in a measure of failure). Effect magnitude was classified according to Cohen (1988).

The assumption of independence of effect sizes is critical when multiple outcomes, intervention types or time points are assessed (Cheung, 2014, 2019; Fernández-Castilla et al., 2020; in sport psychology: Gucciardi et al., 2021). In the present meta-analysis, effect sizes may be nested within studies with different social facilitation conditions compared to the same control group, multiple experiments, or multiple tests. Hence, a three-level meta-analysis was conducted, modelling sampling error (level 1), within-study heterogeneity (level 2) and between-study heterogeneity (level 3; Assink \& Wibbelink, 2016). This addresses 
potential dependencies among effect sizes (Hagger, 2022).

High heterogeneity between the studies was excepted since the experiments vary greatly regarding the population, tasks, and audience manipulations. It is therefore unlikely that the true effect size is the same across all studies. Restricted Maximum Likelihood Estimation (REML) was used to estimate the parameters in the model. Statistical heterogeneity of the effect sizes was explored using $I^{2}, \sigma^{2}$, and $Q$-statistic. Publication bias was modeled with the weight function model (https://vevealab.shinyapps.io/WeightFunctionModel/; Vevea \& Woods, 2005). The weight-function model uses the weighted average of effects, a measure of heterogeneity among effects, and a selection parameter to assess and correct for publication bias. This method is preferred due to its advantages with small sample sizes, higher power (McShane et al., 2016) and good fit when heterogeneity is high (Carter et al., 2019).

To answer the hypotheses, moderator analyses were conducted by pooling the effect of each subgroup. Mixed-effects models were applied when the subgroups at hand were not randomly chosen but represented fixed levels of the moderator of interest (Borenstein \& Higgins, 2013): motor abilities, experimenter's presence and the role of others. Meanwhile, the pooling within the subgroups was conducted using a random-effects model. Due to a lack of sufficient information and a large enough pool of studies, other moderators (e.g., audience size, date of publication) as well as potential interactions between them could not be evaluated.

\section{Results}

The forward literature search on December 6th, 2019, yielded $N=18,030$ articles (see PRISMA 2020 Flow Diagram; Figure 4). After including the records found in unpublished work $(N=7,260)$ and the backward searches $(N=489)$, duplicates were identified. The two independent raters agreed on $99.4 \%$ of all studies ( $\kappa=0.59, p<.001$, moderate agreement). After screening the titles, abstracts and then full-texts, $N=82$ studies ( $N=92$ experiments) were included into the systematic review (sr, see Supplements 3-5, meta-analytic studies highlighted in bold). A list of excluded studies and the reasoning process can be found in Supplement 6. The included studies were published between 1924 and
2019, with a spike of interest around 1970 (Figure 5), coinciding with the three main theoretical schools ${ }^{4}$. Both the systematic-review and meta-analytic sample are described by their main characteristics in Table 1 . The meta-analytic sample was representative regarding most variables. Additional experimental manipulations are listed in Table 2. Overall, $n=39$ experiments compared one social facilitation condition to the solitary condition. All other experiments added at least one more condition to test different theories.

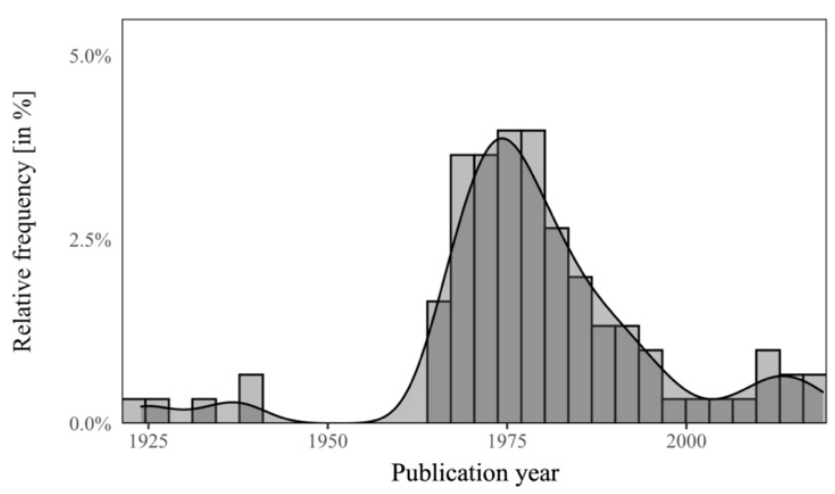

Figure 5. Publication development

\section{Quality characteristics}

Agreement on the quality criteria between the two independent judges was moderately high (agreement: $79.2 \%, \kappa=0.66, p<.001)$. The overall quality was deemed as fair, yet many articles did not report sufficient details to determine the fulfilment of the criteria, especially regarding criterion 3 and 6 (Supplement 2). In $n=42$ studies, the experimenter was physically present (cf. Guerin, 1993), while another $n=20$ articles did not provide sufficient information to exclude the possibility (documented in Supplements 3-5). The meta-analytic effect was not affected by any of the quality criteria individually (not considering criterion 3, which was not fulfilled by any study, and criterion 7 , because only one study reported a power analysis), $F_{\text {all }}<1.9$, $p_{\text {all }}>$.160. Generally, a lack of quality (e.g., no adequate randomization) over- or under-estimated the effect in the expected direction (e.g., slightly stronger effect without randomization).

The systematic review synthesizes all studies by distinguishing first between coordination- and condi-

\footnotetext{
${ }^{4}$ Whenever the sum of experiments reported does not add up to 82 studies/92 experiments, information in the studies was missing to provide the information and categorize them.
} 
tion-oriented tasks to crystallize any trends of inhibition due to reduced attentional capacity in the former and facilitation due to increased drive in the latter. It is supplemented by a meta-analysis of the social facilitation effect and a moderation analysis of the different motor task demands.

Table 1. Overview of all effect characteristics of the systematic review and meta-analysis.

\begin{tabular}{|c|c|c|c|}
\hline & & $\begin{array}{l}\text { Systematic review } \\
\text { ( } n=82 \text { studies, } 92 \text { experiments) }\end{array}$ & $\begin{array}{l}\text { Meta-analysis } \\
\text { ( } n=28 \text { studies, } k=47 \text { effects) }\end{array}$ \\
\hline \multicolumn{4}{|l|}{ Article characteristics } \\
\hline Year of publication & & $1924-2019$ & $1924-2019$ \\
\hline Experimental location & $N$ & $\begin{array}{l}79(86 \%) \text { North America ( } 71 \% \text { USA), } \\
8(9 \%) \text { Europe }\end{array}$ & $\begin{array}{l}39(83 \%) \text { North America }(81 \% \text { USA), } \\
5(11 \%) \text { Europe }\end{array}$ \\
\hline Experimental design & $N$ & $\begin{array}{l}61 \text { between subjects }(66 \%) \text {, } \\
31 \text { within subjects }(34 \%)\end{array}$ & $\begin{array}{l}24 \text { between subjects }(51 \%) \text {, } \\
23 \text { within subjects }(49 \%)\end{array}$ \\
\hline \multicolumn{4}{|l|}{ Sample characteristics } \\
\hline Sample size & & $12-312(M=76.17$, total $=7,008)$ & $12-181(M=58.66$, total $=1,907)$ \\
\hline Gender distribution & & male: $65 \%$ (12 experiments $\mathrm{nr})$ & male: $65 \%$ ( 6 effects $\mathrm{nr})$ \\
\hline Sample age & & $M=17.48$ (range: $6-52$ years) & $M=20.62$ (range: $6-52$ years) \\
\hline Sample population & $N$ & $\begin{array}{l}53 \text { students (mostly p.e. or psychology), } \\
22 \text { minors, } 12 \text { (recreational) athletes }\end{array}$ & $\begin{array}{l}20 \text { students, } \\
14 \text { minors, } 10 \text { (recreational) athletes }\end{array}$ \\
\hline \multicolumn{4}{|l|}{ Audience characteristics } \\
\hline $\begin{array}{l}\text { Role of the other person pre- } \\
\text { sent }\end{array}$ & $N$ & $\begin{array}{l}70 \text { audiences }(76 \%), 18 \text { co-actors }(20 \%) \text {, } \\
4 \text { role of others manipulated }\end{array}$ & 40 audience $(85 \%), 7$ co-actors $(15 \%)$ \\
\hline Physical presence & $N$ & 3 mediated (camera) & 1 mediated (camera) \\
\hline Number of others present & & $\begin{array}{l}M d n=2, M=3.01(S D=3.62, \text { range: } 1-27) \\
6 \text { experiments manipulated number }\end{array}$ & $M d n=2, M=4.28(S D=4.49$, range: $1-27)$ \\
\hline Gender of others & $N$ & $\begin{array}{l}21 \text { experiments entirely female }(23 \%) \text {, } \\
23 \text { experiments entirely male }(25 \%) \text {, } \\
5 \text { experiments investigated gender }(5 \%) \text {, } \\
30 \text { no info }(33 \%)\end{array}$ & $\begin{array}{l}3 \text { studies entirely female }(6 \%), \\
6 \text { studies entirely male }(13 \%), \\
2 \text { studies investigated gender }(4 \%) \text {, } \\
26 \text { no info }(55 \%)\end{array}$ \\
\hline Familiarity of others & $N$ & $\begin{array}{l}22 \text { familiar, } 27 \text { unfamiliar, } \\
37 \text { no info, } 6 \text { manipulated }\end{array}$ & $\begin{array}{l}17 \text { familiar, } 11 \text { unfamiliar, } \\
19 \text { no info }\end{array}$ \\
\hline Experimenter present & $N$ & 47 present $(51 \%)$ & $27(57 \%)$ \\
\hline \multicolumn{4}{|l|}{ Task characteristics } \\
\hline Skill- or condition-based & $N$ & $\begin{array}{l}18 \text { condition }(20 \%), 63 \text { coordination } \\
(69 \%)\end{array}$ & $\begin{array}{l}16 \text { condition }(34 \%), 19 \text { coordination } \\
(40 \%)\end{array}$ \\
\hline Dependent variable & $N$ & $\begin{array}{l}82 \text { performance outcome }(90 \%) \\
9 \text { performance quality }(10 \%)\end{array}$ & $\begin{array}{l}38 \text { performance outcome }(81 \%) \\
9 \text { performance quality }(19 \%)\end{array}$ \\
\hline Familiarity of task & $N$ & $\begin{array}{l}37 \text { familiar task, } 14 \text { unfamiliar task, } \\
3 \text { manipulated, } 30 \text { no info }\end{array}$ & $\begin{array}{l}29 \text { familiar task, } 13 \text { unfamiliar task, } \\
5 \text { no info }\end{array}$ \\
\hline Difficulty of task & $N$ & $\begin{array}{l}21 \text { simple }(25 \%), 14 \text { difficult }(17 \%), \\
31 \text { no info }(37 \%), 19 \text { manipulated }(22 \%)\end{array}$ & $\begin{array}{l}21 \text { simple ( } 45 \%), 13 \text { difficult (28\%), } \\
13 \text { no info }(27 \%)\end{array}$ \\
\hline
\end{tabular}


Table 2. Count of studies with additional experimental manipulations.

\begin{tabular}{|c|c|c|c|c|c|c|c|}
\hline $\begin{array}{l}\text { subject } \\
\text { characteristics }\end{array}$ & $N$ & $\begin{array}{l}\text { audience } \\
\text { characteristics }\end{array}$ & $N$ & $\begin{array}{l}\text { evaluation } \\
\text { apprehension }\end{array}$ & $N$ & task difficulty & $N$ \\
\hline gender & 17 & audience size & 6 & anxiety & 13 & trial/block/learning & 41 \\
\hline age groups & 4 & co-action design & 7 & evaluation & 12 & task difficulty & 10 \\
\hline IQ & 2 & coaction size & 1 & familiarity of audience & 9 & skill level & 9 \\
\hline extraversion & 1 & & & status of audience & 8 & practice & 2 \\
\hline locus of control & 1 & & & gender audience & 5 & task familiarity & 2 \\
\hline self-esteem & 1 & & & skill level audience & 4 & & \\
\hline self-consciousness & 1 & & & & & & \\
\hline
\end{tabular}

Additional factors (e.g., consequences, failure of a prior task, reinforcement, stereotype presentation): $N=5$

\section{Review of research on coordination-based tasks}

Coordination-based exercises have been hypothesized to have high cognitive loads and should thus be negatively affected by distractions like spectators or coactors. Coordination-based tasks can be further sub-divided into tasks with precision- or time pressure (Bös, 1987; Roth, 1982). This is often determined by the given instructions and dependent variable. There is a variety of tasks and social situations that cause substantial variability between the studies. Tasks performed under precision pressure, thereby requiring predominantly accuracy, are computer-based tracking $(n=15)$, gross-motor balance $(n=12)$ and object manipulation with the instruction to be as accurate as possible $(n=6)$. Tasks performed under time pressure, thereby requiring speed while being coordination-based, are manual dexterity tasks $(n=12)$ or the Coincident Timer $(n=3)$. The blind maze task $(n=9)$ and hot wire task $(n=1)$ were often conducted under time pressure and precision pressure ("try to be as fast as possible without making any errors"). Another $n=3$ other coordination-based, yet highly distinct exercises were identified (musical performance: Abrams \& Manstead, 1981; getting dressed: Markus, 1978; driving simulation: Maxwell et al., 2008). The Pursuit Rotor Tracker (hand-eye coordination; Koerth, 1922) was used most frequently $(n=12)$ due to evidence of motivational influences and because most subjects did not have prior experience with the task.

Coordination under precision pressure. According to the capacity hypothesis (Manstead \& Semin, 1980; see also Sanders, 1981), the performance of tasks with precision pressure (characterized by a high cognitive load) should suffer due to the limited attentional capacity. At the beginning of practicing computer-based tracking (Pursuit Rotor Task; Koerth, 1922), the presence of others appeared to be inhibiting (cf. Butki,
1994; not sign.: Haas \& Roberts, 1975; Lombardo \& Catalano, 1978; Martens, 1969a, 1969b; Martens \& Landers, 1969), whereas towards the end of learning or during a retention test (Sawyer \& Noel, 2000), the subjects that learned or performed in the presence of an observing (cf. Iso-Ahola \& Hatfield, 1986) or evaluative (e.g. Martens, 1969a) audience compensated or outperformed the control-group subjects (Butki, 1994; Haas \& Roberts, 1975; Hollifield, 1982; Kieffer, 1977; Travis, 1925), supporting the capacity hypothesis (Manstead \& Semin, 1980). A mirror was not sufficient to cause performance changes (Guerin, 1986; cf. Innes \& Gordon, 1985), refuting the idea that simple distraction may lead to deterioration (Wicklund, 1975). Moreover, interaction effects were found for the participants' sex (Corston \& Colman, 1996; White, 1991), the spectators' status and evaluative potential (F. Miller et al., 1979), whereas Wankel (1977), Martens (1969b) and Martens and Landers (1969) reported no significant main (audience size) or interaction effects (task difficulty, anxiety).

Similarly, balancing, a gross-motor coordinationbased task (Bös, 1987), appeared to be facilitated across studies, although affected by a few limitations. Balance was investigated using stabilometers (Crabbe, 1973; K. M. Johnson, 1974; Kozar, 1973; J. F. Murray, 1983; Singer, 1965; Wankel, 1975), balance boards (Lau et al., 2019) or beam/line walking (MacCracken \& Stadulis, 1985). Another apparatus, inducing higher levels of anxiety/drive and thus a suitable tool to test Zajonc' hypothesis (1965), is the free-standing balance ladder developed by Bachman (1961; see Landers, 1975; Landers \& Landers, 1973; Livingston et al., 1974; Simensky, 1991). Subjects performed better when another human was present (intermittently irrespective of their initial ability; Landers \& Landers, 1973; J. F. Murray, 1983), which would be in line with Zajonc' drive hypothesis rather than Manstead and Semin's capacity hypothesis. Contradictory results 
were presented by MacCracken and Stadulis (1985), who found the social condition to be facilitating when balance ability was high and inhibiting when ability was low, and by Singer (1965), who found athletes with sports experience to be inhibited, while non-athletes were facilitated. Preschoolers performed better alone, as opposed to second-graders (Crabbe, 1973). Nonetheless, in several other experiments, the groups did not differ significantly (Kozar, 1973; Lau et al., 2019; Livingston et al., 1974; Simensky, 1991; Wankel, 1975), however, Livingston et al. (1974, p. 315) and Wankel (1975, p. 214) critically reviewed their own experimental set-up that may have led to the null-findings.

Object manipulation can be examined both under precision and time pressure, depending on the task setup, the instructions, and the dependent variables. Tasks like the "roll-up" game (Martens \& Landers, 1972, p. 350; McCullagh \& Landers, 1976; Sasfy \& Okun, 1974) require high fine-motor skills and precision without any time pressure. Several experiments found no significant difference between the social facilitation and solitary condition (Hall \& Bunker, 1979; Martens \& Landers, 1972; McCullagh \& Landers, 1976), whereas performance decreased in the presence of expert (Sasfy \& Okun, 1974) or evaluative (Martens \& Landers, 1972; Sasfy \& Okun, 1974) others, and when anxiety was high (Hutchinson \& Cotten, 1973; Innes \& Gordon, 1985). This was independent of task difficulty (cf. Martens \& Landers, 1972), aligning with our hypothesis that the additional attentional load negatively affects the cognitive performance in precision-pressure coordination tasks. Co-actors elicited opposing effects in Burwitz and Newell (1972), Hall and Bunker (1979), and Martens and Landers (1972), even though their samples, experimental designs and motor tasks were nearly identical.

Coordination under time pressure. Given the presented theoretical arguments, time pressure during coordination-based tasks may result in controversial findings, because increased drive should facilitate the speedy response, while the attentional load should impair coordination performance. The previously discussed empirical evidence suggests that speed-related tasks are facilitated (Bond \& Titus, 1983; Kaczmarek et al., 2022; Sekiguchi \& Hata, 2019b, 2019a). Time pressure was induced in small-object manipulation tasks by instructing participants to act as fast as possible, either in the presence of a single co-actor (Bird, 1973; Carment, 1970; Carment \& Latchford, 1970; Q. L. Miller, 1989; Wankel, 1972), a small/large (Gates, 1924), same-/opposite-sex (Fouts, 1980; Kenyon \& Loy, 1966), familiar/unfamiliar (Cox, 1966, 1968) or common/prestigious audience (Kenyon \& Loy, 1966). While some were unaffected by their presence (Bird, 1973; Cox, 1966, 1968; Kenyon \& Loy, 1966; Wankel, 1972), others worked faster when paired with a second participant (Q. L. Miller, 1989) or observed by spectators (of the same sex; Fouts, 1980; cf. Wankel, 1972, p. 434; Cox, 1966, 1968). The difference between performing alone or with a co-actor was larger than with an audience (e.g., Bird, 1973; Carment \& Latchford, 1970; El Baden, 1984).

While several experiments used similar versions of the "blind maze" (Hunt \& Hillery, 1973), their social facilitation situations and thus results differ substantially due to their diverging theoretical approaches. Performance scores of the "blind maze" are mainly timebased (speed measure), but some studies have added number of errors (accuracy measure) as additional dependent variable. Pessin and Husband (1933) found direct and indirect observation by familiar or unfamiliar spectators to result in small yet insignificant performance decrements compared to solitary performance, while Shaver and Liebling (1976) reported an interaction effect between task difficulty and others' presence (cf. Landers et al., 1977). Rajecki and colleagues (1977) tested activation- and attention-based theoretical approaches with additional conditions (mirror, mannikin/human spectator with/without blind-fold; cf. Innes \& Gordon, 1985) and found human and especially, but not exclusively, evaluative audiences to be facilitating (cf. Miyamoto, 1979). Additionally, Griffith et al. (1989) presented evidence that several drivemanipulating factors "influenced individual performance in the presence of others in a manner generally consistent with Paulus' (1983) [cognitive-motivational] model" (p. 268).

The study by Markus (1978) is noteworthy: the author asked participants to change out of and into familiar and unfamiliar clothing while either no one, an incidental or an attentive audience was present. This unobtrusive design has high internal validity, as it prevented evaluation apprehension by the experimenter, which strongly resembles the social facilitation effect as hypothesized by Cottrell et al. (1968) and Henchy and Glass (1968). Markus (1978) found a mere presence effect moderated by task difficulty, which is in line with both of Zajonc' assumptions (1965). The attentive audience produced even stronger effects.

Overall, the experiments on motor tasks that rely primarily on information processing (i.e., coordinationbased) differ regarding their samples, tasks, audience conditions and evaluative priming. Most studies on 
both audience and co-action effects did not find a significant difference. In the presence of an audience, the distribution of facilitating and inhibiting effects was fairly balanced. Additionally, the moderating effect of participants' ability level (i.e., learning stage, initial ability, task familiarity) stood out (Haas \& Roberts, 1975; Markus, 1978; Martens, 1969a). Those studies that looked for differences between men and women regarding their response to someone being present $(n=17)$, did not find a significant interaction effect $(n=13)$. A trend of social inhibition can be observed for object control with precision pressure, whereas time pressure may result in a facilitation of an already learned skill. While this has most often been interpreted in the framework of the generalized drive theory (Zajonc, 1965), it does comply with the arguments made by Manstead and Semin (1980): a task performed under precision pressure that is not well-learned yet, requires more cognitive attention and might thus be impaired in the presence of others.

\section{Review of research on condition-based tasks}

Zajonc' drive hypothesis suggests that conditionbased tasks should be facilitated because an increased drive would benefit performance in energy-/effort-determined tasks. The cognitive load of spectators, on the other hand, should not affect the energy-determined tasks that are discussed in the following.

Endurance. Bös (1987) distinguishes between several subcategories of condition-based tasks (see Figure 3). To date, social facilitation experiments have only investigated endurance, strength and strength endurance ( $n=1$ on speed, Ben-Ezra et al., 1986). The results show considerable variability in their methodological and qualitative characteristics. However, there appears to be a facilitating trend in tasks involving sustained performance (endurance \& strength endurance, see Figure 3), in line with the present hypothesis and the results summarized by Strauss (2002). More specifically, Worringham and Messick (1983) found a significant inter-condition and intra-subject increase in running speed when an attentive female was observing the male and female participants (cf. Strube et al., 1981). This is also in line with the learned drive hypothesis by Cottrell et al. (1968). Other endurance-based performances (Shuttle Run: Bowman \& Dunn, 1982; Chevrette, 1968) found a facilitating effect, despite highly confounded control conditions, or a non-significant trend (Thielemier, 2014; unpublished master's thesis). Moreover, performance relying on strength-endurance im- proved significantly when executed with a single (digital) co-actor (Feltz et al., 2011; E. Murray et al., 2016), three co-actors (Kamal, 1980; Martens \& Landers, 1969) or a passive audience (Bowman \& Dunn, 1982; El Baden, 1984; cf. Moede, 1920), whereas Chevrette (1968) did not find a facilitating effect of audience presence on vertical hang performance in a sample of children, and Kenyon and Loy (1966) reported no changes in performance when undergraduate students exerted a submaximal wrist force for as long as possible. El Baden (1984) found co-actors to be more facilitating than a passive audience when doing sit-ups for 60 seconds (although it is worth noting that females achieved nearly as many sit-ups in the co-action condition as the male participants, cf. p. 63).

Strength. Strength determines performance in throwing fastballs (Weinstein et al., 1987), standing broad jump (Bowman \& Dunn, 1982), power exertion towards the ground (Piché \& Sachs, 1982), grip or wrist dynamometer tests (Chevrette, 1968; Kenyon \& Loy, 1966), as well as bench press (Sheridan et al., 2019) and leg extension (Beckmann \& Strang, 1992; Martens \& Landers, 1969). While Bowman and Dunn (1982), Chevrette (1968), and Piché and Sachs (1982) did not find an effect of any type of audience or co-actor presence on performance, maximal lifted weight improved in the leg press (Beckmann \& Strang, 1992) or when lifting a box while being watched by a similar or superior spectator (Selan, 1986). Bench press performance improved significantly for a large majority of participants (Sheridan et al., 2019). Nonetheless, caution needs to be practiced when interpreting the results by Sheridan and colleagues (2019): the strength parameters may improve not only due to social facilitation, but also a changed perception of safety.

\section{Review of research on tasks with coordination- and condition-based aspects}

Tasks requiring both coordination and condition are subject to the speed-accuracy trade-off (Fitts \& Posner, 1967; see also Landers \& McCullagh, 1976), hence, any inhibiting or facilitating effects as expected for condition- or coordination-based aspects, respectively, might cancel each other out. Overall, studies did not find a social facilitation effect. The present experiments tested the social facilitation paradigm in a "natural situation" (Forgas et al., 1980) with mostly unfamiliar observers. Performance was either rated by quality criteria or indicators of accuracy or correct execution. While in gymnastics a social inhibition effect was found (Paulus et al., 1972; Paulus \& Cornelius, 1974; 
however, this can be critically reviewed on the correlating initial scores of the performance changes, see Strauss, 2002), the absence of an audience affected introverts positively when hitting table tennis serves (Graydon \& Murphy, 1995), whereas extroverts improved under observation. Meanwhile, the presence or absence of an audience failed to cause any significant effect on the penalty accuracy for intercollegiate soccer players (Navarro et al., 2013) or basketball free-throw accuracy (Krendl et al., 2012; Welch, 2005). Similarly, skilled karate students were not affected by an audience, whereas lesser skilled students performed worse when not alone (Bell \& Yee, 1989).

Dube and Tatz (1991) evaluated tennis match performance of children, and Forgas et al. (1980) assessed novice and expert squash players. Forgas et al. (1980) specifically described the unobtrusive nature of their experimental setup, whereas during the tennis matches, a referee who was scoring the players' shots, was always present. Both studies investigated and rejected the skill-hypothesis: Dube and Tatz (1991) reported a significant interaction effect between audience presence and the subjects' skill level for all quality measures of performance, whereas Forgas et al. (1980) found no moderating effect of skill level on the social facilitation effect. Nonetheless, it is debatable whether these experiments fully comply with the social facilitation paradigm since both match situations may hold competitive influences. Furthermore, Forgas et al. (1980) discuss the possibility of "automatic matching" (p. 46) to show the audience a good match rather than one's individual best performance.

\section{Meta-analysis}

Only a small proportion of the eligible studies could be included in the meta-analysis (Supplement 3-5). The first three-level random-effects model indicated a small, positive, significant effect, $N=28, k=47, d=0.29$, $95 \%$ CI $[0.03 ; 0.55], p=.030, \mathrm{AIC}=107.49$. The heterogeneity within the model was substantial, $Q(45)=380.39, p_{\mathrm{Q}}<.001$, justifying the choice of a random-effects model. $I^{2}=87 \%$ of the variance was not attributable to sampling error. Within-study variance, $k=47, \sigma_{\text {level } 2}^{2}=0.25, I_{\text {level } 2}^{2}=41.25 \%$, and between-study variance was high, $N=28, \sigma_{\text {level } 3}^{2}=0.23, I_{\text {level } 3}^{2}=45.52 \%$. An inspection of the residuals and Cook's distance (cut-off: $4 / n$ ) per effect did not show any outliers. Figure 6 visualizes all included effects sorted by motor ability: condition $(n=16)$, coordination $(n=19)$ and mixed $(n=12)$.
To check whether the nested data structure improved the model fit, level 2 and level 3 were removed respectively, indicating a significant decrease of model fit when removing level $2, d=0.27,95 \%$ CI $[0.03 ; 0.51]$, $p=.031, \sigma_{\text {level } 3}^{2}=0.32$, AIC $=142.37, \chi^{2}=36.88, p_{\text {fit }}<.001$. When removing level 3 , the model statistics resembled the full model, $d=0.33,95 \%$ CI $[0.10 ; 0.56], p=.006$, but the model fit again decreased significantly, $\sigma^{2}$ level ${ }_{2}=0.52, \mathrm{AIC}=112.26, \chi^{2}=6.77, p_{\mathrm{fit}}=.009$. Hence, the multilevel model is justified.

\section{Moderator analyses}

Moderator analyses were conducted to identify clusters of individual effects that systematically explain the between-study heterogeneity. All coded variables have been argued to moderate the social facilitation effect in previous studies, however, the eligible studies often did not provide (ample) details (e.g., age, audience sex, audience \& task familiarity). Thus, only reasoned variables with sufficient study samples were tested for their moderating effect (Supplement 7). A meta-analytical interaction effect for social facilitation and gender was not possible due to a lack of studies and statistical information.

To answer the hypothesis whether motor tasks with high cognitive demands (coordination under time or precision pressure) are impaired while tasks with high energy demands (condition) or presumably equally high demands (mixed tasks) are affected differently by the presence of others, a mixed-effects model was run. Results showed a significant difference between the estimates of the pooled effects, $F(3,43)=4.18, p=.011$, with $Q(42)=244.92, p<.001, \sigma_{\text {level } 2}^{2}=0.26, \sigma_{\text {level } 3}^{2}=0.1$ (Table 3), indicating that the mixed-effects model was justified. Variability was highest for timed coordination tasks. Additionally, the confidence intervals indicate high inconsistency in all pooled effect sizes except for condition-based tasks.

\section{Sensitivity analysis}

Publication bias was assessed using the weightfunction model for publication bias (McShane et al., 2016; Vevea \& Woods, 2005). Results in the robustness of the meta-analysis are displayed in Table 4. $\chi^{2}$ tests indicated no severe publication bias, $\chi_{\text {all }}^{2}<7.1$, $p_{\text {all }}>$.05. The moderate one- and two-tailed model, effect sizes and variances were similar to the unadjusted estimates. 


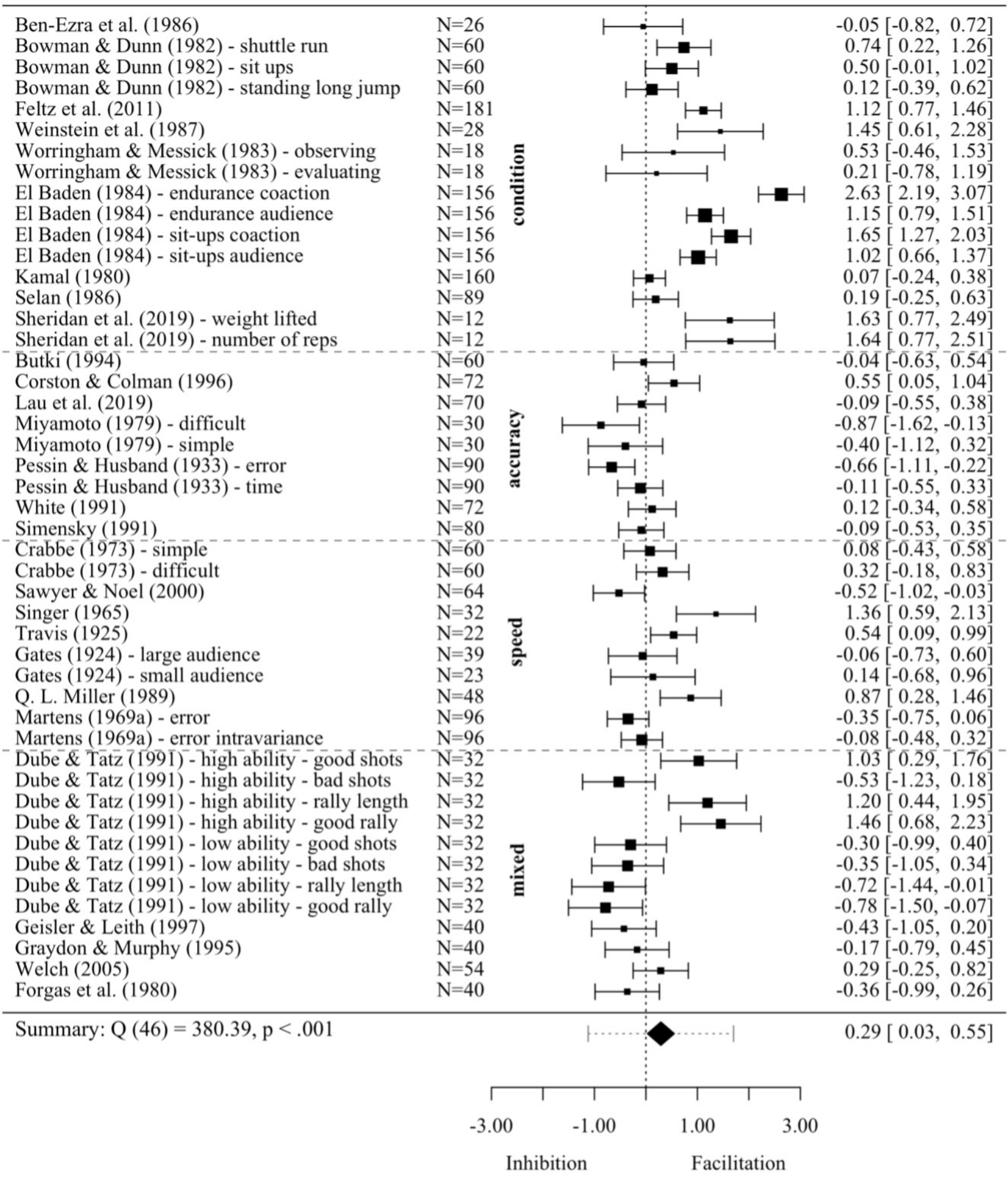

Figure 6. Forest plot of the results of the multilevel model $(\mathrm{d}=$ Cohen's $\mathrm{d}, \mathrm{CI}=$ confidence interval $)$. 
Table 3. Results of moderator analysis based on motor task categories.

\begin{tabular}{lrllll}
\hline Motor ability & $\boldsymbol{k}$ & $\boldsymbol{d}$ & $\boldsymbol{S}$ & $\mathbf{9 5 \%}$ CI & $\boldsymbol{p}_{\text {condition }}$ \\
\hline condition & 16 & 0.84 & 0.17 & CI $[0.46 ; 1.23]$ & \\
coordination under & & & & & \\
- precision pressure & 14 & 0.03 & 0.24 & CI $[-0.88 ; 0.95]$ & .004 \\
- time pressure & 5 & 0.12 & 0.34 & CI $[-1.01 ; 1.26]$ & .061 \\
mixed & 12 & -0.05 & 0.26 & CI $[-1.07 ; 0.97]$ & .007 \\
\hline
\end{tabular}

Table 4. Effect size estimations for various publication bias scenarios.

\begin{tabular}{|c|c|c|c|c|c|}
\hline \multirow[b]{2}{*}{ Moderator } & \multicolumn{5}{|c|}{ Publication bias scenario } \\
\hline & $\begin{array}{c}\text { Unad- } \\
\text { justed } \\
\text { estimate }\end{array}$ & $\begin{array}{c}\text { Severe } \\
\text { one-tailed }\end{array}$ & $\begin{array}{l}\text { Moderate } \\
\text { one-tailed }\end{array}$ & $\begin{array}{l}\text { Moderate } \\
\text { two-tailed }\end{array}$ & $\begin{array}{l}\text { Severe } \\
\text { two-tailed }\end{array}$ \\
\hline Variance component & 0.32 & 0.30 & 0.33 & 0.34 & 0.45 \\
\hline Condition (intercept) & 0.84 & 0.90 & 1.02 & 0.96 & 0.78 \\
\hline $\begin{array}{l}\text { Coordination under } \\
\text { - precision pressure }\end{array}$ & 0.03 & 0.09 & 0.11 & 0.02 & -0.39 \\
\hline - time pressure & 0.12 & 0.07 & 0.20 & 0.11 & -0.25 \\
\hline Mixed & -0.05 & 0.00 & 0.11 & 0.02 & -0.27 \\
\hline Likelihood ratio test & & $\chi^{2}(1)=7.02, p=.867$ & $\chi^{2}(1)=6.13, p=.180$ & $\chi^{2}(2)=6.68, p=.704$ & $\chi^{2}(2)=4.21, p=.059$ \\
\hline
\end{tabular}

Note: Effect sizes for the moderator meta-analysis are provided as Cohen's $d$ per motor tasks category. $p$-value cut-offs are at $.01 \& .05$ (for two-tailed selection methods: $.005 \& .995, .025 \& .975$, respectively).

\section{Discussion}

The present investigation synthesizes the evidence on human social facilitation during motor tasks to test whether condition- and coordination-requirements led to diverging effects due to the hypothesized cognitiveload differences, and whether time and precision pressure during coordination-based tasks are affected differently. The results indicate that coordination-based tasks are not systematically inhibited. While object manipulation performed under precision pressure seems to be inhibited more often than not (at least when the task is not well learned), object manipulation performed under time pressure (and balancing) appear to be facilitated (cf. Bond \& Titus, 1983; Guerin, 1993). Nevertheless, a considerable portion of the experiments did not find a significant difference between executing coordination-based tasks in solitary or in the presence of others, only sometimes moderated by task difficulty/skill level. During condition-based tasks, we found a consistent trend for tasks involving sustained performance to be facilitated through the presence of others. Both running and strength exercises like plank- ing (Feltz et al., 2011) were facilitated through co-actors and spectators. The meta-analysis generally aligned with the systematic review: The subgroup-effect for the condition-based exercises was strongly positive, indicating that (strength) endurance performance was facilitated. The lack of other significant sub-group effects may result from the high heterogeneity of experimental methods, audiences, and motor tasks.

Our findings are support for both the generalized drive theory (Zajonc, 1965) and the capacity hypothesis (Manstead \& Semin, 1980). High performance in condition-based tasks results from high amounts of available energy, which, according to the generalized drive theory (Zajonc, 1965) increase through heightened drive (cf. Strauss, 2002). Contrary to this, coordinationbased task performance is determined by the information uptake and available cognitive resources. The capacity hypothesis suggests that these tasks are therefore affected differently, which is supported by the present results. Additionally, Bös (1987) and Roth (1982) find similarities between coordination-based tasks performed under time pressure and condition-based tasks. The observed non-significant trend of facilitation during speed-reliant coordination tasks is similar to the 
condition-based findings, suggesting that an energy/information-oriented distinction between tasks seems more appropriate to cluster social facilitation effects than a simple/complex distinction. Generally, as proposed by Strauss (2002) and systematically quantified in this review, activation-based models (Zajonc, 1965; Cottrell et al., 1968; Guerin \& Innes, 1982) seem to be applicable for energetically determined tasks (condition), while attention-based models (Manstead \& Semin, 1980; Baron 1986) seem more appropriate for some information-determined tasks (coordination). Hence, future research should target the operationalization of activation and attention processes, e.g., by using condition and coordination exercises rather than simple and complex tasks.

In the studies with tasks requiring both coordination and condition in similar parts, no trend of social facilitation or inhibition was found, potentially because condition-based facilitation was cancelled out by coordination-based inhibition. I.e., certain tasks that are classified as predominantly condition-based may be affected differently due to coordination-demands (cf. timing during standing long jump, Bowman \& Dunn, 1982). Accordingly, a more precise operationalization of condition- and coordination-based motor tasks might be warranted to establish the mechanisms underlying social facilitation.

Our findings generally align with those of previous systematic reviews. Other meta-analyses have had a broader focus (Bond \& Titus, 1983: motor and cognitive tasks; Oviatt \& Iso-Ahola, 2008: more diverse social situations, synthesizing motor tasks). Bond and Titus (1983) reported that in the presence of others, the subjects performed complex tasks less accurately or more slowly and experienced higher arousal, while simple tasks (especially quantitative measures) were executed more quickly (no meta-analytic effect on accuracy or arousal was reported; for recent results, Kaczmarek et al., 2022; Sekiguchi \& Hata, 2019b, 2019a). Strauss (2002) also concluded that while social facilitation effects remain weak throughout the literature, a motor-task taxonomy may help partition the effects - a hypothesis that was supported by the present systematic review and moderator analysis. Additionally, in an interesting archival analysis, Heinrich et al. (2021) compared results from biathlon world cups prior to and during the covid-19 pandemic, looking specifically at the difference between the condition-based and coordination-accuracy based elements. Their analyses found the relationship between motor tasks and social presence to be moderated by gender. This is particularly noteworthy since previous studies did not find such a gender- interaction effect. In our sample of $N=92$ experiments, 17 included gender as an additional factor, however, only four indicated gender-based differences. Since none of the theories provides an explanation for this surprising effect, future analyses are warranted. It should be considered that just because no spectators were physically present during covid-19 competitions, the biathletes were not alone: there are still other athletes co-acting and competing as well as TV audiences and others like coaches or staff, who occasionally gave feedback or support.

\section{Limitations of the evidence included in this synthesis}

Although this review applied strict inclusion and exclusion criteria, it is constrained by the poor to fair quality of most of the screened articles, as assessed by current standards (NHLBI, 2020). These quality ratings should be interpreted with caution: the criteria of the Quality Assessment of Controlled Intervention Studies (NHLBI, 2020; Supplement 2) are fairly strict for older studies (e.g., power analyses only gained in consideration after the seminal review by Cohen, 1962). While this review is a comprehensive summary across 100 years, most studies do not provide sufficient information to neither reject nor assume the fulfillment of the criteria. Future studies should ensure that these modern quality criteria (randomization, blinding, power analysis, quality tests) are met and reported (good example: Krendl et al., 2012). Covering 100 years of research is a strength of the systematic review but may also introduce some bias into the meta-analysis towards more recent evidence: only $11 \%$ of the studies included in the meta-analysis were published before the seminal paper by Zajonc (1965), while $41 \%$ of the included studies were published after Bond and Titus (1983). Hence, there might be a bias in the meta-analytic effect in comparison to the systematic review, and they should only be considered together.

Additional issues more specific to social facilitation research include introducing rivalry (cf. Allport, 1920, 1924; for a historical classification, see Dashiell, 1935; Guerin, 1993) or wanting to make an impression (Burnham, 1910) into the experimental paradigm. Stronger effects can be expected in those studies that did not control for these influences. However, it may very well be that the absence of a mere presence effect stems from the inherent complications of social facilitation research. It is highly difficult to create an experimental situation in which the subject does not feel 
monitored or observed. Markus (1978) provided a pioneering method by using an incidental task (dressing into familiar and unfamiliar clothing) whilst either being alone, with a confederate facing away, or with a confederate watching the dressing. Future research should replicate unobtrusive experimental designs like this to prevent the dilution of the effect. This could for example be achieved with technologies like GPS tracking systems or camera-based motion tracking to create more natural, unobserved scenarios for the subjects. Similar systems have been applied and assessed in electronic monitoring (Laird et al., 2018; however, for individual responses to electronic monitoring, see Ravid et al., 2020).

A major limitation in conducting the experiments is the experimenter's presence during the alone-condition (Dashiell, 1930, 1935). Guerin (1993) had already systematically listed the articles that violated this principle of social facilitation research. In the present meta-analysis, the social facilitation effect was half as strong when the experimenter was reportedly in the same room as the subject during the alone-condition, which further amplifies the importance to reduce the experimenter's physical and potentially evaluative presence in this field of research to establish a true mere presence or audience effect. Additionally, the lack of protocols to control for other influences and the low comparability of the study designs (cf. Aiello \& Douthitt, 2001) are backed by our quantitative analyses (cf. Guerin, 1993).

Additional complications of synthesizing the present studies arise from the high heterogeneity of active and passive others, their evaluative potential, and how task difficulty was operationalized. The original idea (dichotomic: "well learned", "novel"; generalized drive theory; Zajonc, 1965) was soon shifted to task complexity ("simple" vs "complex"). However, authors only rarely provide reasonable arguments as to which version of a task was considered simple or complex (e.g. Pursuit Rotor Task speeds of 30rpm or 60rpm, F. Miller et al., 1979), or to whom the task may appear simple or complex (subjectively and a posteriori defined experts vs. novices, for a critical discussion, see Strauss, 2002). These operationalizations complicate the comparability of the included studies and the true effect task difficulty may have in mere presence situations.

\section{Practical application}

With the observed trend, it may be possible to implement social facilitation effects in certain contexts, e.g., physical-education classes or condition training, while preventing social inhibition effects during tasks requiring coordination under precision pressure until they are well-learned. Technical skills with high degrees of cognitive load should be performed alone in the beginning of learning. To gather more conclusive evidence for the relationship between coordination and the capacity hypothesis, measures of both speed and accuracy requirements in the same experiment or even same motor task are necessary. First examples of explicitly testing the hypotheses by Strauss (2002) were recently set in a rat population (Sekiguchi \& Hata, $2019 \mathrm{~b}$ ) as well as a human population (Kaczmarek et al., 2022): performance in the plank task was facilitated in the presence of spectators, but speed-stacking was inhibited.

Additionally, it may be interesting to study the effects of virtual audiences in the future (Liu \& $\mathrm{Pu}, 2020$ ). Dashiell (1930) already argued that physical presence is not necessary for social facilitation or inhibition, as long as the subject has the impression that someone is working on the task simultaneously (see e.g., Feltz et al., 2011). This may hold important implications for virtual teams and electronic performance monitoring to reduce social inhibition effects during learning (Claypoole \& Szalma, 2019; Davidson \& Henderson, 2000). Nonetheless, individual differences and responses to social situations should be considered (Uziel, 2007).

\section{Future research}

Our findings advocate an integrated framework of activation- and attention-oriented social facilitation theories. To empirically confirm this hypothesis, future research should target the operationalization of activation and attention processes, e.g., by using conditionand coordination-based exercises rather than simple and complex tasks, ideally within the same experiment. Important requisites for these studies are the precise operationalization of condition- and coordination-based motor tasks, the application of modern quality criteria (see NHLBI, 2020), and social facilitation specific considerations like controlling for competition effects, the impact of the experimenter's presence, and providing a definition of task difficulty (task difficulty/complexity, skill level or learning).

Once these processes are understood in their purest form, additional concepts like gender effects (see Heinrich et al., 2021), virtual audiences (e.g., Claypoole \& Szalma, 2019) or motivational states can be integrated (already suggested by Blascovich et al, 1999; Paulus, 
1983). E.g., in the Theory of Challenge and Threat States in Athletes, Jones et al. (2009) and Meijen et al. (2020) have expanded the framework of Blascovich et al. (1999) to include emotional/motivational consequences of primary and secondary appraisal, which affect the potential to meet situational demands and explain potential controversial effects of social presence.

\section{Conclusion}

To summarize, this systematic review and metaanalysis align previous findings (Bond \& Titus, 1983; Landers \& McCullagh, 1976; Strauss, 2002): tasks that predominantly rely on energetic processes are facilitated by the active or passive presence of others, as are tasks performed under time pressure or balancing tasks, whereas tasks that require accuracy are either inhibited or remain unaffected, with no obvious pattern, supporting the hypothesis by Strauss (2002). Since we cover 100 years of research, the methodological quality of the included studies is somewhat limited with respect to current requirements and standards of our inclusion criteria. Therefore, the meta-analysis might be biased towards more recent evidence, hence, the systematic review and meta-analysis should only be considered together. In the previous paragraphs, we have highlighted the quality criteria specific for clean social facilitation conditions during motor task performances and provided suggestions for future research. Most importantly, all information required by quality assessment tools should be reported, the influence of the experimenter as an additional evaluative spectator should be eliminated, and key statistical information should be provided (key statistical information: sample sizes, means and standard deviations per condition, correlations between related samples). Specific to sports and motor tasks, direct comparisons of the effect of spectators or co-actors on condition- and coordination-based tasks is warranted to establish conclusively how activation or attention processes determine the direction of the effect. The distinction of simple/well-learned and complex tasks seems less appropriate in the motor learning and sports context. Despite a decline in this area of research, many questions remain unanswered, see already Aiello and Douthitt (2001).

\section{References}

Abrams, D., \& Manstead, A. S. R. (1981). A test of theories of social facilitation using a musical task. British Journal of Social Psychology, 20(4), 271-278. https://doi.org/10.1111/j.20448309.1981.tb00497.x
Aiello, J. R., \& Douthitt, E. A. (2001). Social facilitation from triplett to electronic performance monitoring. Group Dynamics: Theory, Research, and Practice, 5(3), 163-180. https://doi.org/10.1037/1089-2699.5.3.163

Allport, F. H. (1920). The influence of the group upon association and thought. Journal of Experimental Psychology, 3(3), 159182. https://doi.org/10.1037/h0067891

Allport, F. H. (1924). Response to social stimulation in the group. In F. H. Allport (Ed.), Social psychology (1st ed., pp. 260-291). Erlbaum.

Assink, M., \& Wibbelink, C. J. M. (2016). Fitting three-level metaanalytic models in R: A step-by-step tutorial. The Quantitative Methods for Psychology, 12(3), 154-174. https://doi.org/10.20982/tqmp.12.3.p154

Bachman, J. C. (1961). Specificity vs. generality in learning and performing two large muscle motor tasks. Research Quarterly of the American Association for Health, Physical Education and Recreation, 32(1), 3-11. https://doi.org/10.1080/10671188.1961.10762064

Balduzzi, S., Rücker, G., \& Schwarzer, G. (2019). How to perform a meta-analysis with R: A practical tutorial. Evidence-Based Mental Health, 22(4), 153-160. https://doi.org/10.1136/ebmental-2019-300117

Baron, R. S. (1986). Distraction-conflict theory: Progress and problems. Advances in Experimental Social Psychology, 19(C), 140. https://doi.org/10.1016/S0065-2601(08)60211-7

Becker, B. J. (1988). Synthesizing standardized mean change measures. British Journal of Mathematical and Statistical Psychology, 41(2), 257-278. https://doi.org/10.1111/j.20448317.1988.tb00901.x

Becker, B. J. (2009). Model-based meta-analysis. In H. Cooper, L. Hedges, \& J. Valentine (Eds.), The handbook of research synthesis and meta-analysis (2nd ed., pp. 377-395). Russell Sage Foundation.

Beckmann, J., \& Strang, H. (1992). Soziale Hemmung und Förderung bei schwierigen Aufgaben. Zeitschrift Für Sozialpsychologie, 23(1), 83-91.

Bell, P. A. (1989). Skill level and audience effects on performance of a karate drill. Journal of Social Psychology, 129(2), 191-200. https://doi.org/10.1080/00224545.1989.9711720

Ben-Ezra, V., French, R., Mastro, J., \& Montelione, T. (1986). Influence of coactors on performance of visually impaired runners. Perceptual and Motor Skills, 62(3), 889-890. https://doi.org/10.2466/pms.1986.62.3.889

Bird, A. M. (1973). Effects of social facilitation upon females' performance of two psychomotor tasks. Research Quarterly of the American Association for Health, Physical Education and Recreation, $44(3), \quad 322-330$ https://doi.org/10.1080/10671188.1973.10615210

Blascovich, J., Ernst, J. M., Tomaka, J., Kelsey, R. M., Salomon, K. L., \& Fazio, R. H. (1993). Attitude accessibility as a moderator of autonomic reactivity during decision making. Journal of Personality and Social Psychology, 64(2), 165-176. https://doi.org/10.1037/0022-3514.64.2.165

Blascovich, J., Mendes, W. B., Hunter, S. B., \& Salomon, K. (1999). Social 'facilitation' as challenge and threat. Journal of Personality and Social Psychology, 77(1), 68-77. https://doi.org/10.1037/0022-3514.77.1.68

Bond, C. F., \& Titus, L. J. (1983). Social facilitation: A meta-analysis of 241 studies. Psychological Bulletin, 94(2), 265-292. https://doi.org/10.1037/0033-2909.94.2.265

Borenstein, M., \& Higgins, J. P. T. (2013). Meta-analysis and subgroups. Prevention Science, 14(2), 134-143. https://doi.org/10.1007/s11121-013-0377-7 
Bös, K. (1987). Handbuch sportmotorischer tests. Verlag für Psychologie.

Bös, K., Schlenker, L., Albrecht, C., Büsch, D., Lämmle, L., Müller, H., Oberger, J., \& Tittlbach, S. (2009). Deutscher Motorik-Test 6-18 (DMT 6-18). Czwalina.

Bowman, R. A., \& Dunn, J. M. (1982). Effect of peer presence on psychomotor measures with EMR children. Exceptional Children, $48(5)$, 449-451. https://doi.org/10.1177/001440298204800508

Burnham, W. H. (1910). The group as a stimulus to mental activity. Science, 31(803), 761-767. https://doi.org/10.1126/science.31.803.761

Burwitz, L., \& Newell, K. M. (1972). The effects of the mere presence of coactors on learning a motor skill. Journal of Motor Behavior, 4(2), 99-102. https://doi.org/10.1080/00222895.1972.10734924

Butki, B. D. (1994). Adaptation to effects of an audience during acquisition of rotary pursuit skill. Perceptual and Motor Skills, 79(3), 1151-1159.

Carment, D. W. (1970). Rate of simple motor responding as a function of coaction, competition, and sex of the participants. Psychonomic Science, 19(6), 342-343. https://doi.org/10.3758/BF03328849

Carment, D. W., \& Latchford, M. (1970). Rate of simple motor responding as a function of coaction, sex of the participants, and the presence or absence of the experimenter. Psychonomic Science, 20(4), 253-254. https://doi.org/10.3758/BF03329050

Carter, E. C., Schönbrodt, F. D., Gervais, W. M., \& Hilgard, J. (2019). Correcting for bias in psychology: A comparison of meta-analytic methods. Advances in Methods and Practices in Psychological Science, 2(2), 115-144. https://doi.org/10.1177/2515245919847196

Cheung, M. W. L. (2014). Modeling dependent effect sizes with three-level meta-analyses: A structural equation modeling approach. Psychological Methods, 19(2), 211-229. https://doi.org/10.1037/a0032968

Cheung, M. W. L. (2019). A guide to conducting a meta-analysis with Non-independent effect sizes. Neuropsychology Review, 29(4), 387-396. https://doi.org/10.1007/s11065-019-09415-6

Chevrette, J. M. (1968). The effect of peer observation on selected tests of physical performance. Journal of Psychology: Interdisciplinary and Applied, 70(1), 113-119. https://doi.org/10.1080/00223980.1968.10543488

Claypoole, V. L., \& Szalma, J. L. (2019). Electronic performance monitoring and sustained attention: Social facilitation for modern applications. Computers in Human Behavior, 94, 25-34. https://doi.org/10.1016/j.chb.2019.01.001

Clayton, D. A. (1978). Socially facilitated behavior. The Quarterly Review of Biology, 53(4), 373-392. https://doi.org/10.1086/410789

Cohen, J. (1962). The statistical power of abnormal-social psychological research: A review. The Journal of Abnormal and Social Psychology, 65(3), 145-153. https://doi.org/10.1037/h0045186

Cohen, J. (1988). Statistical power analysis for the behavioral sciences (2nd ed.). Routledge.

Corston, R., \& Colman, A. M. (1996). Gender and social facilitation effects on computer competence and attitudes toward computers. Journal of Educational Computing Research, 14(2), 171-183. https://doi.org/10.2190/7VW3-W6RV-6DCP-70MN

Cottrell, N. B. (1968). Performance in the presence of other human beings: Mere presence, audience, and affiliation effects. In E. C. Simmel, R. A. Hoppe, \& G. A. Milton (Eds.), Social facilitation and imitative behavior (pp. 91-110). Allyn \& Bacon.
Cottrell, N. B. (1972). Social facilitation. In C. G. McClintock (Ed.), Experimental social psychology (pp. 185-236). Rinehart and Winston.

Cox, F. N. (1966). Some effects of test anxiety and presence or absence of other persons on boys' performance on a repetitive motor task. Journal of Experimental Child Psychology, 3(1), 100 112. https://doi.org/10.1016/0022-0965(66)90065-8

Cox, F. N. (1968). Some relationships between test anxiety, presence or absence of male persons, and boy's performance on a repetitive motor task. Journal of Experimental Child Psychology, 6(1), 1-12. https://doi.org/10.1016/0022-0965(68)90066-0

Crabbe, J. M. (1973). Social facilitation effects on children during early stages of motor learning [Doctoral dissertation, University of Iowa]. ProQuest Dissertations and Theses Global.

Danziger, K. (2000). Making social psychology experimental: A conceptual history, 1920-1970. Journal of the History of the Behavioral Sciences, 36(4), 329-347. https://doi.org/10.1002/1520-6696(200023)36:4

Dashiell, J. F. (1930). An experimental analysis of some group effects. Journal of Abnormal and Social Psychology, 25(2), 190 199. https://doi.org/10.1037/h0075144

Dashiell, J. F. (1935). Experimental studies of the influence of social situations on the behavior of individual human adults. In E. Murchinson (Ed.), A handbook of social psychology (pp. 1097 1158). Clark University Press.

Davidson, R., \& Henderson, R. (2000). Electronic performance monitoring: A laboratory investigation of the influence of monitoring and difficulty on task performance, mood state, and selfreported stress levels. Journal of Applied Social Psychology, 30(5), 906-920. https://doi.org/10.1111/j.15591816.2000.tb02502.x

Dube, S. K., \& Tatz, S. J. (1991). Audience effects in tennis performance. Perceptual and Motor Skills, 73(3), 844-846. https://doi.org/10.2466/pms.1991.73.3.844

El Baden, B. M. (1984). The effect of peer presence upon healthrelated physical fitness test scores of college students [Doctoral Dissertation, Oregon State University]. ProQuest Dissertations and Theses Global.

Feltz, D. L., Kerr, N. L., \& Irwin, B. C. (2011). Buddy up: The Köhler effect applied to health games. Journal of Sport and Exercise Psychology, 33(4), 506-526. https://doi.org/10.1123/jsep.33.4.506

Féré, C. (1887). Sensation et movement: Etudes experimentales de psycho-mécanique. Alcan.

Fernández-Castilla, B., Jamshidi, L., Declercq, L., Beretvas, S. N., Onghena, P., \& Van den Noortgate, W. (2020). The application of meta-analytic (multi-level) models with multiple random effects: A systematic review. Behavior Research Methods, 52(5), 2031-2052. https://doi.org/10.3758/s13428-020-01373-9

Fitts, P. M., \& Posner, M. I. (1967). Human performance. Brooks/Cole.

Fleishman, E. A. (1957). Factor structure in relation to task difficulty in psychomotor performance. Educational and Psychological Measurement, 17(4), 522-532. https://doi.org/10.1177/001316445701700408

Forgas, J. P., Brennan, G., Howe, S., Kane, J. F., \& Sweet, S. (1980). Audience effects on squash players' performance. Journal of Social Psychology, 111(1), 41-47. https://doi.org/10.1080/00224545.1980.9924271

Fouts, G. T. (1980). Effect of sex of audience on speed of performance of preadolescents. Perceptual and Motor Skills, 51(2), 565-566. https://doi.org/10.2466/pms.1980.51.2.565

Gamer, M., Lemon, J., \& Singh, P. (2019). Package 'irr': various coefficients of interrater reliability and agreement. CRAN. 
Gates, G. S. (1924). The effect of an audience upon performance. Editorial Comment Upon the Effect of an Audience. Journal of Abnormal Psychology and Social Psychology, 18(4), 334-342. https://doi.org/10.1037/h0075628

Geen, R. G., \& Gange, J. J. (1977). Drive theory of social facilitation: Twelve years of theory and research. Psychological Bulletin, 84(6), 1267-1288. https://doi.org/10.1037/00332909.84.6.1267

Graydon, J., \& Murphy, T. (1995). The effect of personality on social facilitation whilst performing a sports related task. Personality and Individual Differences, 19(2), 265-267. https://doi.org/10.1016/0191-8869(95)00052-8

Griffith, T. L., Fichman, M., \& Moreland, R. L. (1989). Social loafing and social facilitation: An empirical test of the cognitive-motivational model of performance. Basic and Applied Social Psychology, 10(3), 253-271. https://doi.org/10.1207/s15324834basp1003 4

Groff, B. D., Baron, R. S., \& Moore, D. L. (1983). Distraction, attentional conflict, and drivelike behavior. Journal of Experimental Social Psychology, 19(4), 359-380. https://doi.org/10.1016/0022-1031(83)90028-8

Gucciardi, D. F., Lines, R. L. J., \& Ntoumanis, N. (2021). Handling effect size dependency in meta-analysis. International Review of Sport and Exercise Psychology, 15(1), 1-27. https://doi.org/10.1080/1750984X.2021.1946835

Guerin, B. (1986). The effects of mere presence on a motor task. Journal of Social Psychology, 126(3), 399-401. https://doi.org/10.1080/00224545.1986.9713602

Guerin, B. (1993). Social facilitation. Cambridge University Press.

Guerin, B., \& Innes, J. M. (1982). Social facilitation and social monitoring: A new look at Zajonc's mere presence hypothesis. British Journal of Social Psychology, 21(1), 7-18. https://doi.org/10.1111/j.2044-8309.1982.tb00506.x

Haas, J., \& Roberts, G. C. (1975). Effect of evaluative others upon learning and performance of a complex motor task. Journal of Motor Behavior, 7(2), 81-90. https://doi.org/10.1080/00222895.1975.10735017

Hagger, M. (2022). Meta-analysis. International Review of Sport and Exercise Psychology, 15(1), 1-32. https://doi.org/10.1080/1750984X.2021.1966824

Hall, E. G., \& Bunker, L. K. (1979). Locus of control as a mediator of social facilitation effects during motor skill learning. Journal of Sport Psychology, 1(4), 332-335. https://doi.org/10.1123/jsp.1.4.332

Harrer, M., Cuijpers, P., Furukawa, T., \& Ebert, D. D. (2019a). dmetar: Companion R Package For The Guide 'Doing MetaAnalysis in R'. http://dmetar.protectlab.org/

Harrer, M., Cuijpers, P., Furukawa, T., \& Ebert, D. D. (2019b). Doing meta-analysis in $R: A$ hands-on guide. Chapman \& Hall/CRC Press.

Hedges, L. V., \& Olkin, I. (2014). Statistical methods for metaanalysis. Academic Press.

Heinrich, A., Müller, F., Stoll, O., \& Cañal-Bruland, R. (2021). Selection bias in social facilitation theory? Audience effects on elite biathletes' performance are gender-specific. Psychology of Sport and Exercise, 55, 101943. https://doi.org/10.1016/J.PSYCHSPORT.2021.101943

Henchy, T., \& Glass, D. C. (1968). Evaluation apprehension and the social facilitation of dominant and subordinate responses. Journal of Personality and Social Psychology, 10(4), 446-454. https://doi.org/10.1037/h0026814
Higgins, J. P. T., \& Green, S. (2011). Cochrane Handbook for Systematic Reviews of Interventions Version 5.1.0 (updated March 2011). The Cochrane Collaboration. Available from training.cochrane.org/handbook/archive/v5.1/

Hollifield, N. L. (1982). Effect of prior performance experience before audiences on a dominant and nondominant motor response. Journal of Sport Psychology, 4(4), 317-323. https://doi.org/10.1123/jsp.4.4.317

Hollingworth, H. L. (1935). The psychology of the audience. American Book Company. https://doi.org/10.1037/11245-000

Hull, C. L. (1943). Principles of behavior (1st ed.). Appleton-Century-Crofts.

Hunt, P. J., \& Hillery, J. M. (1973). Social facilitation in a coaction setting: An examination of the effects over learning trials. Journal of Experimental Social Psychology, 9(6), 563-571. https://doi.org/10.1016/0022-1031(73)90038-3

Hutchinson, V. Q., \& Cotten, D. J. (1973). Effects of audience and anxiety level on learning and performance of a complex gross motor skill by college women. Perceptual \& Motor Skills, 36(3_suppl),

1103-1108. https://doi.org/10.2466/pms.1973.36.3c.1103

Innes, J. M., \& Gordon, M. I. (1985). The effects of mere presence and a mirror on performance of a motor task. The Journal of Social Psychology, 125(4), 479-484. https://doi.org/10.1080/00224545.1985.9713527

Iso-Ahola, S., \& Hatfield, B. D. (1986). Psychology of sports: A social psychological approach. William C Brown Pub.

Johnson, B. T., \& Eagly, A. H. (2014). Meta-analysis of research in social and personality psychology. In H. T. Reis, \& C. M. Judd (Eds.), Handbook of research methods in social and personality psychology (pp. 677-709). Cambridge University Press.

Johnson, K. M. (1974). The effect of passive audiences on the motor performance and autonomic arousal level of college women [Doctoral dissertation, University of Southern California]. ProQuest Dissertations and Theses Global.

Jones, M., Meijen, C., McCarthy, P. J., \& Sheffield, D. (2009). A theory of challenge and threat states in athletes. International Review of Sport and Exercise Psychology, 2(2), 161-180. https://doi.org/10.1080/17509840902829331

Kaczmarek, C., Schmidt, A., Emperle, A. S., \& Schaefer, S. (2022). The influence of social contexts on motor and cognitive performance: Performing alone, in front of others, or coacting with others. Journal of Sport \& Exercise Psychology, 44(2), 1-9. https://doi.org/10.1123/jsep.2021-0101

Kamal, A. F. (1980). Social environment and incentives as motivators in swimming [Doctoral dissertation, Indiana University]. ProQuest Dissertations and Theses Global.

Kenyon, G. S., \& Loy, J. W. Jr. (1966). Soziale Beeinflussung der Leistung bei vier psychomotorischen Aufgaben. In G. Lüschen (Ed.), Kleingruppenforschung und gruppe im sport (10th ed., pp. 192-202). Westdeutscher Verlag.

Kieffer, L. F. (1977). The relationship of trait anxiety, peer presence, task difficulty, and skill acquisition of sixth grade boys. Middle School Research Selected Studies, 1-3(1), 107-115. https://doi.org/10.1080/08851700.1977.11670190

Koenig, A. M., Eagly, A. H., Mitchell, A. A., \& Ristikari, T. (2011). Are leader stereotypes masculine? A meta-analysis of three research paradigms. Psychological Bulletin, 137(4), 616-642. https://doi.org/10.1037/a0023557

Koerth, W. (1922). A pursuit apparatus: Eye-hand coordination. Psychological Monographs, 31(1), 288-292. https://doi.org/10.1037/h0093169 
Kozar, B. (1973). The effects of a supportive and nonsupportive audience upon learning a gross motor skill. International Journal of Sport Psychology, 4(1), 11-30.

Krendl, A., Gainsburg, I., \& Ambady, N. (2012). The effects of stereotypes and observer pressure on athletic performance. Journal of Sport \& Exercise Psychology, 34(1), 3-15. https://doi.org/10.1123/jsep.34.1.3

Laird, B. K., Bailey, C. D., \& Hester, K. (2018). The effects of monitoring environment on problem solving performance. The Journal of Social Psychology, 158(2), 215-219. https://doi.org/10.1080/00224545.2017.1324396

Lämmle, L., Tittlbach, S., Oberger, J., Worth, A., \& Bös, K. (2010). A Two-level model of motor performance ability. Journal of Exercise Science and Fitness, 8(1), 41-49. https://doi.org/10.1016/S1728-869X(10)60006-8

Landers, D. (1975). Observational learning of a motor skill: Temporal spacing of demonstrations and audience presence. Journal of Motor Behavior, 7(4), 281-287. https://doi.org/10.1080/00222895.1975.10735047

Landers, D., Bauer, R. S., \& Feltz, D. L. (1978). Social facilitation during the initial stage of motor learning: A re-examination of Martens' audience study. Journal of Motor Behavior, 10(4), 325-337. https://doi.org/10.1080/00222895.1978.10735166

Landers, D., Brawley, L. R., \& Hale, B. D. (1977). Habit strength differences in motor behavior: The effects of social facilitation paradigms and subject sex [Doctoral dissertation, Pennsylvania State University]. ProQuest Dissertations and Theses Global.

Landers, D., \& Landers, D. (1973). Effects of model's presence and performance level on motor behavior. Journal of Motor Behavior, $\quad 5(3)$, https://doi.org/10.1080/00222895.1973.10734958

Landers, D., \& McCullagh, P. D. (1976). Social facilitation of motor performance. Exercise and Sport Sciences Reviews, 4(1), 125-162. https://doi.org/10.1249/00003677-197600040-00006

Latané, B. (1981). The psychology of social impact. American Psychologist, 36(4), 343-356. https://doi.org/10.1037/0003066X.36.4.343

Lau, A., Schwarz, J., \& Stoll, O. (2019). Influence of social facilitation on learning development using a Wii balanceboard (TM). German Journal of Exercise and Sport Research, 49(1), 97-102. https://doi.org/10.1007/s12662-018-0562-8

Liu, N., \& Pu, Q. (2020). Can smart voice assistant induce social facilitation effect? A preliminary study. In P. L. Rau (Ed.), International Conference on Human-Computer Interaction (pp. 616-624). Springer.

Livingston, M. V., Landers, D., \& Dorrance, P. B. (1974). Communications: Comparison of coacting individuals' motor performance for varying combinations of initial ability. Research Quarterly of the American Alliance for Health, Physical Education and Recreation, 45(3), 310-317. https://doi.org/10.1080/10671315.1974.10615275

Lombardo, J. P., \& Catalano, J. F. (1978). Failure and its relationship to the social facilitation effect: Evidence for a learned drive interpretation of the social facilitation effect. Perceptual and Motor Skills, $\quad 46(3), \quad 823-829$. https://doi.org/10.2466/pms.1978.46.3.823

Lüdecke, D. (2019). esc: Effect size computation for meta analysis (Version 0.5.1). https://doi.org/10.5281/zenodo.1249218

MacCracken, M. J., \& Stadulis, R. E. (1985). Social facilitation of young children's dynamic balance performance. Journal of Sport Psychology, 7(2), 150-15016. https://doi.org/10.1123/jsp.7.2.150
Manstead, A. S. R., \& Semin, G. R. (1980). Social facilitation effects: Mere enhancement of dominant responses? British Journal of Social and Clinical Psychology, 19(2), 119-135. https://doi.org/10.1111/j.2044-8260.1980.tb00937.x

Markus, H. (1978). The effect of mere presence on social facilitation: An unobtrusive test. Journal of Experimental Social Psychology, 14(4), 389-397. https://doi.org/10.1016/00221031(78)90034-3

Martens, R. (1969a). Palmar sweating and the presence of an audience. Journal of Experimental Social Psychology, 5(3), 371374. https://doi.org/10.1016/0022-1031(69)90061-4

Martens, R. (1969b). Effect of an audience on learning and performance of a complex motor skill. Journal of Personality and Social Psychology, 12(3), 252-260. https://doi.org/10.1037/h0027710

Martens, R., \& Landers, D. (1969). Coaction effects on a muscular endurance task. Research Quarterly of the American Association for Health, Physical Education and Recreation, 40(4), 733-737. https://doi.org/10.1080/10671188.1969.10614911

Martens, R., \& Landers, D. (1972). Evaluation potential as a determinant of coaction effects. Journal of Experimental Social Psychology, 8(4), 347-359. https://doi.org/10.1016/00221031(72)90024-8

Martin, J. J. (2020). What Triplett didn't find and what Lewin never said first. Kinesiology Review, 9(2), 89-91. https://doi.org/10.1123/kr.2020-0006

Maxwell, J. P., Masters, R., \& Poolton, J. M. (2008). Self-consciousness, perceived evaluation and performance of a continuous motor task. International Journal of Sport Psychology, 39(3), 179-191.

McCullagh, P. D., \& Landers, D. (1976). Size of audience and social facilitation. Perceptual and Motor Skills, 42(3), 1067-1070. https://doi.org/10.2466/pms.1976.42.3c.1067

McShane, B. B., Böckenholt, U., \& Hansen, K. T. (2016). Adjusting for publication bias in meta-analysis: An evaluation of selection methods and some cautionary notes. Perspectives on Psychological $\quad$ Science, $\quad 11(5), \quad 730-749$. https://doi.org/10.1177/1745691616662243

Meijen, C., Turner, M., Jones, M. V., Sheffield, D., \& McCarthy, P. (2020). A theory of challenge and threat states in athletes: A revised conceptualization. Frontiers in Psychology, 11, Article 126. https://doi.org/10.3389/fpsyg.2020.00126

Miller, F., Hurkman, M. F., \& Feinberg, R. A. (1979). Status and evaluation potential in the social facilitation and impairment of task performance. Personality and Social Psychology Bulletin, 5(3), 381-385. https://doi.org/10.1177/014616727900500323

Miller, Q. L. (1989). The effects of social facilitation on persons performing a manual work task. Occupational Therapy in Mental Health, 9(3), 21-30. https://doi.org/10.1300/J004v09n03_03

Miyamoto, M. (1979). Social facilitation in finger maze learning. Japanese Psychological Research, 21(2), 94-98. https://doi.org/10.4992/psycholres 1954.21.94

Moede, W. (1920). Experimentelle Massenpsychologie: Beiträge zur Experimental psychologie der Gruppe. Hirzel.

Moher, D., Liberati, A., Tetzlaff, J., Altman, D. G., \& PRISMA Group, T. (2009). Preferred reporting items for systematic reviews and meta-analyses: The PRISMA statement. PLoS Medicine, 6(7), e1000097. https://doi.org/10.1371/journal.pmed 1000097

Morris, S. B., \& DeShon, R. P. (2002). Combining effect size estimates in meta-analysis with repeated measures and independentgroups designs. Psychological Methods, 7(1), 105-125. https://doi.org/10.1037/1082-989X.7.1.105 
Murray, E., Neumann, D. L., Moffitt, R. L., \& Thomas, P. R. (2016). The effects of the presence of others during a rowing exercise in a virtual reality environment. Psychology of Sport and Exercise, 22 , $328-336$. https://doi.org/10.1016/j.psychsport.2015.09.007

Murray, J. F. (1983). Effects of alone and audience on motor performance for males and females. International Journal of Sport Psychology, 14(2), 92-97.

Navarro, M., van der Kamp, J., Ranvaud, R., \& Savelsbergh, G. J. P. (2013). The mere presence of a goalkeeper affects the accuracy of penalty kicks. Journal of Sports Sciences, 31(9), 921929. https://doi.org/10.1080/02640414.2012.762602

Newell, K. M. (2020). What are fundamental motor skills and what is fundamental about them? Journal of Motor Learning and Development, 8(2), 280-314. https://doi.org/10.1123/JMLD.20200013

NHLBI. (2020). Study quality assessment tools. https:/www.nhlbi.nih.gov/health-topics/studyquality-assessment-tools

Ouzzani, M., Hammady, H., Fedorowicz, Z., \& Elmagarmid, A. (2016). Rayyan - A web and mobile app for systematic reviews. Scientific Reviews, 5, Article 210. https://doi.org/10.1186/s13643-016-0384-4

Oviatt, D. P. (2005). Social facilitation and motor performance: A meta-analysis. University of Maryland, College Park.

Oviatt, D. P., \& Iso-Ahola, S. (2008). Social facilitation and motor/athletic performance. In J. H. Humphrey (Ed.), Sports and athletics development (pp. 3-25). Nova Science Publishers.

Page, M. J., McKenzie, J. E., Bossuyt, P. M., Boutron, I., Hoffmann, T. C., Mulrow, C. D., Shamseer, L., Tetzlaff, J. M., Akl, E. A., Brennan, S. E., Chou, R., Glanville, J., Grimshaw, J. M., Hróbjartsson, A., Lalu, M. M., Li, T., Loder, E. W., Mayo-Wilson, E., McDonald, S.,...Moher, D. (2021). The PRISMA 2020 statement: An updated guideline for reporting systematic reviews. British Medical Journal, 372, Article n71. https://doi.org/10.1136/bmj.n71

Park, S. H., Uiga, L., \& Masters, R. S. W. (2022). Crowd reception influences avoidance behavior during football penalty-kicks, but you wouldn't know it: A retrospective analysis of professional games. Psychology of Sport and Exercise, 61, 102169. https://doi.org/10.1016/j.psychsport.2022.102169

Paulus, P. B. (1983). Group influence on individual task performance. In P. B. Paulus (Ed.), Basic group processes (pp. 97120). Springer.

Paulus, P. B., \& Cornelius, W. L. (1974). An analysis of gymnastic performance under conditions of practice and spectator observation. Research Quarterly of the American Alliance for Health, Physical Education and Recreation, 45(1), 56-63. https://doi.org/10.1080/10671188.1974.10615240

Paulus, P. B., Shannon, J. C., Wilson, D. L., \& Boone, T. D. (1972). The effect of spectator presence on gymnastic performance in a field situation. Psychonomic Science, 29(2), 88-90. https://doi.org/10.3758/BF03336578

Pessin, J., \& Husband, R. W. (1933). Effects of social stimulation on human maze learning. Journal of Abnormal and Social Psychology, 28(2), 148-154. https://doi.org/10.1037/h0074711

Piché, A., \& Sachs, M. L. (1982). Influence of friendship on performance on a noncompetitive task. Perceptual \& Motor Skills, 54(3_suppl),

$1212-1214$ https://doi.org/10.2466/pms.1982.54.3c.1212

Rajecki, D. W., Ickes, W., Corcoran, C., \& Lenerz, K. (1977). Social facilitation of human performance: Mere presence effects. Journal of Social Psychology, 102(2), 297-310. https://doi.org/10.1080/00224545.1977.9713277
Ravid, D. M., Tomczak, D. L., White, J. C., \& Behrend, T. S. (2020). EPM 20/20: A review, framework, and research agenda for electronic performance monitoring. Journal of Management, 46(1), 100-126. https://doi.org/10.1177/0149206319869435

R Core Team. (2019). R: A language and environment for statistical computing. R Foundation for Statistical Computing.

Roth, K. (1982). Strukturanalyse koordinativer Fähigkeiten: Empirische Überprüfung koordinationstheoretischer Konzepte. In K. Roth, \& K. Willimczik (Eds.), Bewegungswissenschaft (pp. 227-287). Rowohlt.

Sanders, G. S. (1981). Driven by distraction: An integrative review of social facilitation theory and research. Journal of Experimental Social Psychology, 17(3), 227-251. https://doi.org/10.1016/0022-1031(81)90024-X

Sasfy, J., \& Okun, M. (1974). Form of evaluation and audience expertness as joint determinants of audience effects. Journal of Experimental Social Psychology, 10(5), 461-467. https://doi.org/10.1016/0022-1031(74)90014-6

Sawyer, D. T., \& Noel, F. J. (2000). Effect of an audience on learning a novel motor skill. Perceptual and Motor Skills, 91, 539545. https://doi.org/10.2466/pms.2000.91.2.539

Schmidt, R. A., \& Wrisberg, C. A. (2000). Motor learning and performance. Human Kinetics.

Sekiguchi, Y., \& Hata, T. (2019a). A task for assessing the impact of a partner on the speed and accuracy of motor performance in rats. Journal of Visualized Experiments, 2019(152), 1-9. https://doi.org/10.3791/60176

Sekiguchi, Y., \& Hata, T. (2019b). Effects of the mere presence of conspecifics on the motor performance of rats: Higher speed and lower accuracy. Behavioural Processes, 159(2019), 1-8. https://doi.org/10.1016/j.beproc.2018.12.012

Selan, J. L. (1986). Effect of psychosocial variables on maximum acceptable weight of lift [Presentation]. Proceedings of the $\mathrm{Hu}-$ man Factors Society - 30th Annual Meeting.

Shamseer, L., Moher, D., Clarke, M., Ghersi, D., Liberati, A., Petticrew, M., Shekelle, P., Stewart, L., \& Group, P. R. I. S. M. A.P. (2015). Preferred reporting items for systematic review and meta-analysis protocols (PRISMA-P) 2015: Elaboration and explanation. British Medical Journal, 2(349), g7647. https://doi.org/10.1186/2046-4053-4-1

Shaver, P., \& Liebling, B. (1976). Explorations in the drive theory of social facilitation. The Journal of Social Psychology, 99(2), 259-271. https://doi.org/10.1080/00224545.1976.9924779

Sheridan, A., Marchant, D. C., Williams, E. L., Jones, H. S., Hewitt, P. A., \& Sparks, A. (2019). Persence of spotters improves bench press performance: A deception study. Journal of Strength and Conditioning Research, 33(7), 1755-1761. https://doi.org/10.1519/JSC.0000000000002285

Shiffrin, R. M., \& Schneider, W. (1977). Controlled and automatic human information processing: II. Perceptual learning, automatic attending and a general theory. Psychological Review, 84(2), 127-190. https://doi.org/10.1037/0033-295X.84.2.127

Simensky, S. G. (1991). The effects of an evaluative audience upon college males' self-efficacy, perceived ability, anxiety, and learning of a novel motor task [Master's thesis, Michigan State University]. ProQuest Dissertations and Theses Global.

Singer, R. N. (1965). Effect of spectators on athletes and non-athletes performing a gross motor task. Research Quarterly of the American Association for Health, Physical Education and Recreation, $36(4), \quad 473-482$ https://doi.org/10.1080/10671188.1965.10614722

Spence, K. W. (1956). Behavior theory and conditioning. Yale University Press. 
Steinmetz, J., \& Pfattheicher, S. (2017). Beyond social facilitation: A review of the Far-reaching effects of social attention. Social Cognition, $35(5)$ 585-599. https://doi.org/10.1521/soco.2017.35.5.585

Strauss, B. (2002). Social facilitation in motor tasks: A review of research and theory. Psychology of Sport and Exercise, 3(3), 237-256. https://doi.org/10.1016/S1469-0292(01)00019-X

Stroebe, W. (2012). The truth about Triplett (1898). But Nobody Seems to Care. Perspectives on Psychological Science, 7(1), 5457. https://doi.org/10.1177/1745691611427306

Strube, M. J., Miles, M. E., \& Finch, W. H. (1981). The social facilitation of a simple task: Field tests of alternative explanations. Personality and Social Psychology Bulletin, 7(4), 701-707. https://doi.org/10.1177/014616728174030

Thielemier, L. E. (2014). Effects of audience presence on running performance [Master's thesis, Arkensas State University]. ProQuest Dissertations and Theses Global.

Travis, L. E. (1925). The effect of a small audience upon eye-hand coordination. Journal of Abnormal Psychology and Social Psychology, 20(2), 142-146. https://doi.org/10.1037/h0071311

Triplett, N. (1898). The dynamogenic factors in pacemaking and competition. The American Journal of Psychology, 9(4), 507 533. https://doi.org/10.2307/1412188

Utesch, T., Bardid, F., Büsch, D., \& Strauss, B. (2019). The relationship between motor competence and physical fitness from early childhood to early adulthood: A meta-analysis. Sports Medicine, 49(4), 541-551. https://doi.org/10.1007/s40279-01901068-y

Uziel, L. (2007). Individual differences in the social facilitation effect: A review and meta-analysis. Journal of Research in Personality, 41(3), 579-601. https://doi.org/10.1016/j.jrp.2006.06.008

Vevea, J. L., \& Woods, C. M. (2005). Publication bias in research synthesis: Sensitivity analysis using a priori weight functions. Psychological Methods, 10(4), 428-443. https://doi.org/10.1037/1082-989X.10.4.428

Viechtbauer, W. (2010). Conducting meta-analyses in R with the metafor package. Journal of Statistical Software, 36(3), 1-48. https://doi.org/10.18637/jss.v036.i03

Wankel, L. M. (1972). Competition in motor performance: An experimental analysis of motivational components. Journal of Experimental Social Psychology, 8(5), 427-437. https://doi.org/10.1016/0022-1031(72)90068-6
Wankel, L. M. (1975). The effects of social reinforcement and audience presence upon the motor performance of boys with different levels of initial ability. Journal of Motor Behavior, 7(3), 207-216.https://doi.org/10.1080/00222895.1975.10735035

Wankel, L. M. (1977). Audience size and trait anxiety effects upon state anxiety and motor performance. Research Quarterly of the American Alliance for Health, Physical Education and Recreation, $\quad 48(1), \quad 181-186$. https://doi.org/10.1080/10671315.1977.10762168

Weinstein, L., Prather, G. A., \& De Man, A. F. (1987). College baseball pitchers' throwing velocities as a function of awareness of being clocked. Perceptual and Motor Skills, 64(3_suppl), 1185-1186. https://doi.org/10.2466/pms.1987.64.3c.1185

Welch, S. M. (2005). Effects of restricted environmental stimulation therapy and social facilitation on performance enhancement [Doctoral dissertation, Washington State University]. ProQuest Dissertations and Theses Global.

Welk, G. J. (1999). The youth physical activity promotion model: A conceptual bridge between theory and practice. Quest, 51(1), 5-23. https://doi.org/10.1080/00336297.1999.10484297

White, S. A. (1991). Effects of gender and competitive coaction on motor performance. Perceptual and motor skills, 73(2), 581582. https://doi.org/10.2466/pms.1991.73.2.581

Wicklund, R. A. (1975). Objective self-awareness. In L. Berkowitz (Ed.), Advances in experimental social psychology (Vol. 8, pp. 233-275). Academic Press, Inc. https://doi.org/10.1016/S00652601(08)60252-X

Worringham, C. J., \& Messick, D. M. (1983). Social facilitation of running: An unobtrusive study. Journal of Social Psychology, 121(1), 23-29. https://doi.org/10.1080/00224545.1983.9924462

Zajonc, R. B. (1965). Social facilitation. Science, 149(3681), 142 146. https://doi.org/10.1126/science.149.3681.269

Zajonc, R. B. (1980). Feeling and thinking-preferences need no inferences. American Psychologist, 35(2), 151-175. https://doi.org/10.1037/0003-066X.35.2.151

Zajonc, R. B., Heingartner, A., \& Herman, E. M. (1969). Social enhancement and impairment of performance in the cockroach. Journal of Personality and Social Psychology, 13(2), 83-92. https://doi.org/10.1037/h0028063 
Supplement 1. Search strategy per database.

\begin{tabular}{|c|c|c|c|}
\hline Database & Date & Search strategy & Limited to \\
\hline Scopus & 2019-12-06 & $\begin{array}{l}\text { TITLE-ABS-KEY ("social facilitation" OR coaction OR co-action OR "mere presence" OR au- } \\
\text { dience) AND ("motor task" OR athletic OR sport OR physical OR exercise OR movement) }\end{array}$ & \\
\hline PsycINFO & 2019-12-06 & $\begin{array}{l}\text { TX ("social facilitation" OR coaction OR co-action OR "mere presence" OR audience) } \\
\text { AND ("motor task" OR athletic OR sport OR physical OR exercise OR movement)) }\end{array}$ & \\
\hline Web of Science & 2019-12-06 & $\begin{array}{l}\text { ("social facilitation" OR coaction OR co-action OR "mere presence" OR audience) } \\
\text { AND ("motor task" OR athletic OR sport OR physical OR exercise OR movement) (all fields) }\end{array}$ & \\
\hline Academic Search Premier & 2019-12-06 & $\begin{array}{l}\text { TX ("social facilitation" OR coaction OR co-action OR "mere presence" OR audience) } \\
\text { AND ("motor task" OR athletic OR sport OR physical OR exercise OR movement) }\end{array}$ & \\
\hline ProQuest Dissertations & $2022-02-08$ & $\begin{array}{l}\text { noft(("social facilitation" OR coaction OR co-action OR "mere presence" OR audience) } \\
\text { AND ("motor task" OR athletic OR sport OR physical OR exercise OR movement)) }\end{array}$ & $\begin{array}{l}\text { Date until 2019- } \\
12-06\end{array}$ \\
\hline OvidSP & $2022-02-08$ & $\begin{array}{l}\text { ("social facilitation" OR coaction OR co-action OR "mere presence" OR audience) } \\
\text { AND ("motor task" OR athletic OR sport OR physical OR exercise OR movement) }\end{array}$ & $\begin{array}{l}\text { 1860-2019, no re- } \\
\text { lated terms }\end{array}$ \\
\hline
\end{tabular}


Supplement 2. Quality assessment.

Quality Assessment of Controlled Intervention Studies (NHLBI, 2020)

1. Was the method of randomization adequate (i.e., use of randomly generated assignment)?

2. Were study participants and providers blinded to treatment group assignment?

3. Were the people assessing the outcomes blinded to the participants' group assignments?

4. Were the groups similar at baseline on important characteristics that could affect outcomes (e.g., demographics, baseline performance)?

5. Did the authors conduct a manipulation check?

6. Were outcomes assessed using valid and reliable measures, implemented consistently across all study participants? (valid \& reliable as indicated by the authors)

7. Did the authors report that the sample size was sufficiently large to be able to detect a difference in the main outcome between groups with at least $80 \%$ power?

8. Were outcomes reported or subgroups analyzed prespecified (i.e., identified before analyses were conducted)? (Interpreted as only analyzing the proposed hypothesis, no further analyses)

\begin{tabular}{|c|c|c|c|c|c|c|c|c|c|c|c|}
\hline Reference & $N_{\text {alone }}$ & $N_{S F}$ & 1 & 2 & 3 & 4 & 5 & 6 & 7 & 8 & Rating \\
\hline Abel (1938) - Exp. 1 & 74 & $\mathrm{rm}$ & & $\checkmark$ & - & $\checkmark$ & & & - & - & * \\
\hline Abel (1938) - Exp. 2 & 74 & $\mathrm{rm}$ & & & - & $\checkmark$ & & & - & - & $*$ \\
\hline Abrams et al. (1981) & 20 & 60 & $\checkmark$ & $\checkmark$ & - & $\checkmark$ & $\checkmark$ & $\checkmark$ & - & $\checkmark$ & $* * *$ \\
\hline Beckmann \& Strang (1992) & 80 & $\mathrm{rm}$ & & - & - & & & & - & $\checkmark$ & $*$ \\
\hline Bell \& Yee (1989) & 33 & $\mathrm{rm}$ & - & $\checkmark$ & - & $\checkmark$ & & - & - & $\checkmark$ & $*$ \\
\hline Ben-Ezra et al. (1986) & 13 & $\mathrm{rm}$ & $\checkmark$ & & - & & & $\checkmark$ & - & $\checkmark$ & $*$ \\
\hline Bird (1973) & 15 & 30 & $\checkmark$ & & - & & & & - & $\checkmark$ & $*$ \\
\hline Bowman \& Dunn (1982) & 30 & $\mathrm{rm}$ & $\checkmark$ & & - & & & $\checkmark$ & - & $\checkmark$ & $*$ \\
\hline Burwitz \& Newell (1972) & 36 & 72 & $\checkmark$ & & - & & & & - & $\checkmark$ & $*$ \\
\hline Butki (1994) & 15 & 45 & $\checkmark$ & & - & $\checkmark$ & & & - & $\checkmark$ & $*$ \\
\hline Carment (1970) & 10 & 10 & $\checkmark$ & $\checkmark$ & - & & & & - & $\checkmark$ & $*$ \\
\hline Carment \& Latchford (1970) & & & $\checkmark$ & $\checkmark$ & - & & & & - & $\checkmark$ & $*$ \\
\hline Chevrette (1968) & & & $\checkmark$ & & - & & & $\checkmark$ & - & $\checkmark$ & $*$ \\
\hline Corston \& Colman (1996) & 24 & 48 & $\checkmark$ & $\checkmark$ & - & & $\checkmark$ & & - & $\checkmark$ & $* *$ \\
\hline Cox (1966) - Exp. 1 & $20^{*}$ & $40 *$ & $\checkmark$ & & - & $\checkmark$ & & & - & $\checkmark$ & $*$ \\
\hline Cox (1966) - Exp. 2 & $20^{*}$ & $60 *$ & $\checkmark$ & & - & $\checkmark$ & & & - & $\checkmark$ & $*$ \\
\hline Cox (1966) - Exp. 3 & $20 *$ & $40 *$ & $\checkmark$ & & - & $\checkmark$ & & & - & $\checkmark$ & $*$ \\
\hline Cox (1968) - Exp. 1 & $20 *$ & $40 *$ & $\checkmark$ & & - & $\checkmark$ & & & - & $\checkmark$ & $*$ \\
\hline Cox (1968) - Exp. 2 & $20^{*}$ & $60 *$ & $\checkmark$ & & - & $\checkmark$ & & & - & $\checkmark$ & $*$ \\
\hline Cox (1968) - Exp. 3 & $20 *$ & $40 *$ & $\checkmark$ & & - & $\checkmark$ & & & - & $\checkmark$ & $*$ \\
\hline Crabbe (1973) & 30 & 30 & & & - & & & $\checkmark$ & - & - & $*$ \\
\hline D. M. Landers (1975) & 45 & 90 & $\checkmark$ & & - & & - & & - & $\checkmark$ & $*$ \\
\hline D. M. Landers \& Landers (1973) & 20 & 20 & $\checkmark$ & & - & & - & & - & $\checkmark$ & $*$ \\
\hline Dube \& Tatz (1991) & 16 & $\mathrm{rm}$ & $\checkmark$ & $\checkmark$ & - & $\checkmark$ & & - & - & $\checkmark$ & $* *$ \\
\hline E. G. Murray et al. (2016) & 20 & 40 & $\checkmark$ & & - & $\checkmark$ & $\checkmark$ & & - & $\checkmark$ & $* *$ \\
\hline El Baden (1984) & 104 & 208 & $\checkmark$ & & - & & & $\checkmark$ & $\checkmark$ & $\checkmark$ & $* *$ \\
\hline F. G. Miller et al. (1979) & 5 & 20 & $\checkmark$ & & - & & & & - & $\checkmark$ & $*$ \\
\hline
\end{tabular}




\begin{tabular}{|c|c|c|c|c|c|c|c|c|c|c|c|}
\hline Reference & $N_{\text {alone }}$ & $N_{\mathrm{SF}}$ & 1 & 2 & 3 & 4 & 5 & 6 & 7 & 8 & Rating \\
\hline Feltz et al. (2011) & 49 & 132 & $\checkmark$ & & - & $\checkmark$ & $\checkmark$ & $\checkmark$ & - & $\checkmark$ & $* *$ \\
\hline Forgas et al. (1980) & 40 & $\mathrm{rm}$ & $\checkmark$ & & - & $\checkmark$ & - & & - & $\checkmark$ & $*$ \\
\hline Fouts (1980) & 48 & $\mathrm{rm}$ & & & - & & & & - & $\checkmark$ & $*$ \\
\hline Gates (1924) & 25 & 37 & & & - & & $\checkmark$ & & - & - & $*$ \\
\hline Geisler \& Leith (1997) & 20 & 20 & $\checkmark$ & & - & & $\checkmark$ & $\checkmark$ & - & $\checkmark$ & $* *$ \\
\hline Graydon \& Murphy (1995) & 20 & $\mathrm{rm}$ & & & - & & & & - & $\checkmark$ & $*$ \\
\hline Griffith et al. (1989) & 32 & $\mathrm{rm}$ & $\checkmark$ & $\checkmark$ & - & $\checkmark$ & $\checkmark$ & & - & $\checkmark$ & $* *$ \\
\hline Guerin (1986) & 39 & $\mathrm{rm}$ & & & - & & & & - & $\checkmark$ & $*$ \\
\hline Haas \& Roberts (1975) & 45 & $\mathrm{rm}$ & $\checkmark$ & $\checkmark$ & - & $\checkmark$ & & & - & $\checkmark$ & $* *$ \\
\hline Hall \& Bunker (1979) & 32 & $\mathrm{rm}$ & $\checkmark$ & & - & $\checkmark$ & & & - & $\checkmark$ & $*$ \\
\hline Hollifield (1982) & 20 & 20 & $\checkmark$ & - & - & $\checkmark$ & & & - & $\checkmark$ & $*$ \\
\hline Hutchinson \& Cotton (1973) & 144 & $\mathrm{rm}$ & & & - & $\checkmark$ & $\checkmark$ & & - & $\checkmark$ & $*$ \\
\hline Innes \& Gordon (1985) & 20 & 40 & $\checkmark$ & & - & & $\checkmark$ & & - & - & $*$ \\
\hline J. F. Murray (1983) & 42 & 42 & $\checkmark$ & & - & $\checkmark$ & $\checkmark$ & & - & $\checkmark$ & $* *$ \\
\hline Johnson (1974) & 24 & 24 & $\checkmark$ & $\checkmark$ & - & $\checkmark$ & & & - & $\checkmark$ & $* *$ \\
\hline Kamal (1980) & 80 & $\mathrm{rm}$ & $\checkmark$ & & - & $\checkmark$ & $\checkmark$ & & - & $\checkmark$ & $* *$ \\
\hline Kenyon \& Loy (1966) & & & $\checkmark$ & - & - & $\checkmark$ & & $\checkmark$ & - & $\checkmark$ & $* *$ \\
\hline Kieffer (1977) & & & $\checkmark$ & & - & $\checkmark$ & $\checkmark$ & & - & $\checkmark$ & $* *$ \\
\hline Kozar (1973) & 50 & 100 & $\checkmark$ & & - & & $\checkmark$ & & - & $\checkmark$ & $*$ \\
\hline Krendl et al. (2012) & 38 & 36 & $\checkmark$ & $\checkmark$ & $\checkmark$ & $\checkmark$ & $\checkmark$ & $\checkmark$ & - & $\checkmark$ & $* * *$ \\
\hline Landers, Brawley, \& Hale (1977) & 36 & 72 & $\checkmark$ & $\checkmark$ & - & $\checkmark$ & $\checkmark$ & $\checkmark$ & - & $\checkmark$ & $* * *$ \\
\hline Lau et al. (2019) & 35 & 35 & $\checkmark$ & & - & & & & - & $\checkmark$ & $*$ \\
\hline Livingston et al. (1974) & & & $\checkmark$ & & - & $\checkmark$ & & $\checkmark$ & - & $\checkmark$ & $* *$ \\
\hline Lombardo \& Catalano (1975) & 12 & 12 & & - & - & & $\checkmark$ & & - & $\checkmark$ & $*$ \\
\hline Lombardo \& Catalano (1978) & 30 & 31 & & $\checkmark$ & - & & & & - & $\checkmark$ & $*$ \\
\hline MacCracken \& Stadulis (1985) & 99 & $\mathrm{rm}$ & $\checkmark$ & & - & $\checkmark$ & & & - & $\checkmark$ & $*$ \\
\hline Markus (1978) & 15 & 30 & $\checkmark$ & $\checkmark$ & - & & $\checkmark$ & & - & $\checkmark$ & $* *$ \\
\hline Martens (1969a) & 48 & 48 & $\checkmark$ & & - & $\checkmark$ & $\checkmark$ & $\checkmark$ & - & $\checkmark$ & $* *$ \\
\hline Martens (1969b) & 48 & 48 & $\checkmark$ & & - & $\checkmark$ & $\checkmark$ & & - & $\checkmark$ & $* *$ \\
\hline Martens (1969c) & 24 & 24 & & & - & $\checkmark$ & $\checkmark$ & $\checkmark$ & - & $\checkmark$ & $* *$ \\
\hline Martens \& Landers (1969a) & 60 & 120 & & & - & $\checkmark$ & $\checkmark$ & & - & $\checkmark$ & $*$ \\
\hline Martens \& Landers (1972) & 24 & 108 & $\checkmark$ & & - & & & $\checkmark$ & - & $\checkmark$ & $*$ \\
\hline Maxwell et al. (2008) & 28 & $\mathrm{rm}$ & $\checkmark$ & & - & $\checkmark$ & $\checkmark$ & $\checkmark$ & - & $\checkmark$ & $* *$ \\
\hline McCullagh \& Landers (1976) & 16 & 80 & $\checkmark$ & - & - & & - & $\checkmark$ & - & $\checkmark$ & $*$ \\
\hline Miyamoto (1979) & 15 & 15 & $\checkmark$ & $\checkmark$ & - & & & & - & $\checkmark$ & $*$ \\
\hline Navarro et al. (2013) & 10 & $\mathrm{rm}$ & & & - & $\checkmark$ & & & - & $\checkmark$ & $*$ \\
\hline Paulus \& Cornelius (1974) & & & $\checkmark$ & & - & $\checkmark$ & & $\checkmark$ & - & $\checkmark$ & $* *$ \\
\hline Paulus et al. (1972) - Exp. 1 & 24 & $\mathrm{rm}$ & $\checkmark$ & $\checkmark$ & - & & & & - & $\checkmark$ & $*$ \\
\hline Paulus et al. (1972) - Exp. 2 & 21 & $\mathrm{rm}$ & & $\checkmark$ & - & & & & - & $\checkmark$ & $*$ \\
\hline Pessin \& Husband (1933) & 30 & 60 & & & - & & & & - & - & $*$ \\
\hline
\end{tabular}




\begin{tabular}{|c|c|c|c|c|c|c|c|c|c|c|c|}
\hline Reference & $N_{\text {alone }}$ & $N_{\mathrm{SF}}$ & 1 & 2 & 3 & 4 & 5 & 6 & 7 & 8 & Rating \\
\hline Piche \& Sachs (1982) & 24 & 24 & & - & - & & - & & - & $\checkmark$ & $*$ \\
\hline Q. L. Miller (1989) & 24 & 24 & $\checkmark$ & & - & & & & - & $\checkmark$ & * \\
\hline Rajecki et al. (1977) & 10 & 50 & $\checkmark$ & $\checkmark$ & - & & - & & - & $\checkmark$ & $*$ \\
\hline Sasfy \& Okun (1974) & 24 & 72 & $\checkmark$ & $\checkmark$ & - & & $\checkmark$ & $\checkmark$ & - & $\checkmark$ & $* *$ \\
\hline Sawyer \& Noel (2000) & 32 & $\mathrm{rm}$ & $\checkmark$ & & - & $\checkmark$ & & & - & $\checkmark$ & $*$ \\
\hline Selan (1986) & 30 & 30 & & & - & & & & - & $\checkmark$ & $*$ \\
\hline Shaver \& Liebling (1976) - Exp. 1 & 30 & $\mathrm{rm}$ & & $\checkmark$ & - & & & & - & $\checkmark$ & $*$ \\
\hline Shaver \& Liebling (1976) - Exp. 2 & 16 & 48 & & $\checkmark$ & - & & & & - & $\checkmark$ & $*$ \\
\hline Sheridan et al. (2019) & 12 & $\mathrm{rm}$ & & $\checkmark$ & - & $\checkmark$ & $\checkmark$ & $\checkmark$ & - & $\checkmark$ & $* *$ \\
\hline Simensky (1991) & 40 & 40 & $\checkmark$ & $\checkmark$ & - & $\checkmark$ & $\checkmark$ & $\checkmark$ & - & $\checkmark$ & $* * *$ \\
\hline Singer (1965) & 32 & $\mathrm{rm}$ & & & - & $\checkmark$ & & & - & $\checkmark$ & * \\
\hline Singer (1970) & 40 & 40 & $\checkmark$ & & - & & & & - & $\checkmark$ & $*$ \\
\hline Strube et al. (1981) - Exp. 1 & 40 & 80 & $\checkmark$ & & - & & - & & - & $\checkmark$ & $*$ \\
\hline Strube et al. (1981) - Exp. 2 & & & $\checkmark$ & & - & & $\checkmark$ & & - & $\checkmark$ & $*$ \\
\hline Thielemier \& Church (2014) & 17 & $\mathrm{rm}$ & & & - & & & & - & $\checkmark$ & $*$ \\
\hline Travis (1925) & 22 & $\mathrm{rm}$ & & & - & & & & - & - & $*$ \\
\hline Wankel (1972) & & & $\checkmark$ & $\checkmark$ & - & & $\checkmark$ & $\checkmark$ & - & $\checkmark$ & $* *$ \\
\hline Wankel (1975) & 48 & 48 & $\checkmark$ & $\checkmark$ & - & & & & - & $\checkmark$ & $*$ \\
\hline Wankel (1977) & 20 & 40 & $\checkmark$ & $\checkmark$ & - & & $\checkmark$ & & - & $\checkmark$ & $* *$ \\
\hline Weinstein et al. (1987) & 14 & $\mathrm{rm}$ & & & - & & & & - & $\checkmark$ & $*$ \\
\hline Welch (2005) & 27 & $\mathrm{rm}$ & $\checkmark$ & & - & & & & - & $\checkmark$ & $*$ \\
\hline White (1991) & 36 & 36 & $\checkmark$ & $\checkmark$ & - & & & & - & $\checkmark$ & $*$ \\
\hline Worringham \& Messick (1983) & 12 & 24 & $\checkmark$ & $\checkmark$ & - & - & & & - & $\checkmark$ & $*$ \\
\hline
\end{tabular}

Note: $\checkmark=$ criterion fulfilled; $-=$ criterion not fulfilled; empty $=$ no information provided; $r m=$ repeated measures. $N_{\mathrm{SF}}$ denotes all subjects in all included social-facilitation conditions (up to 5, cf. Rajecki et al., 1977; McCullagh \& Landers, 1976). Cox $(1966,1969)$ : Ns not explicitly stated, derived from design. 
Supplement 3. Social facilitation manipulation in coordination-based tasks.

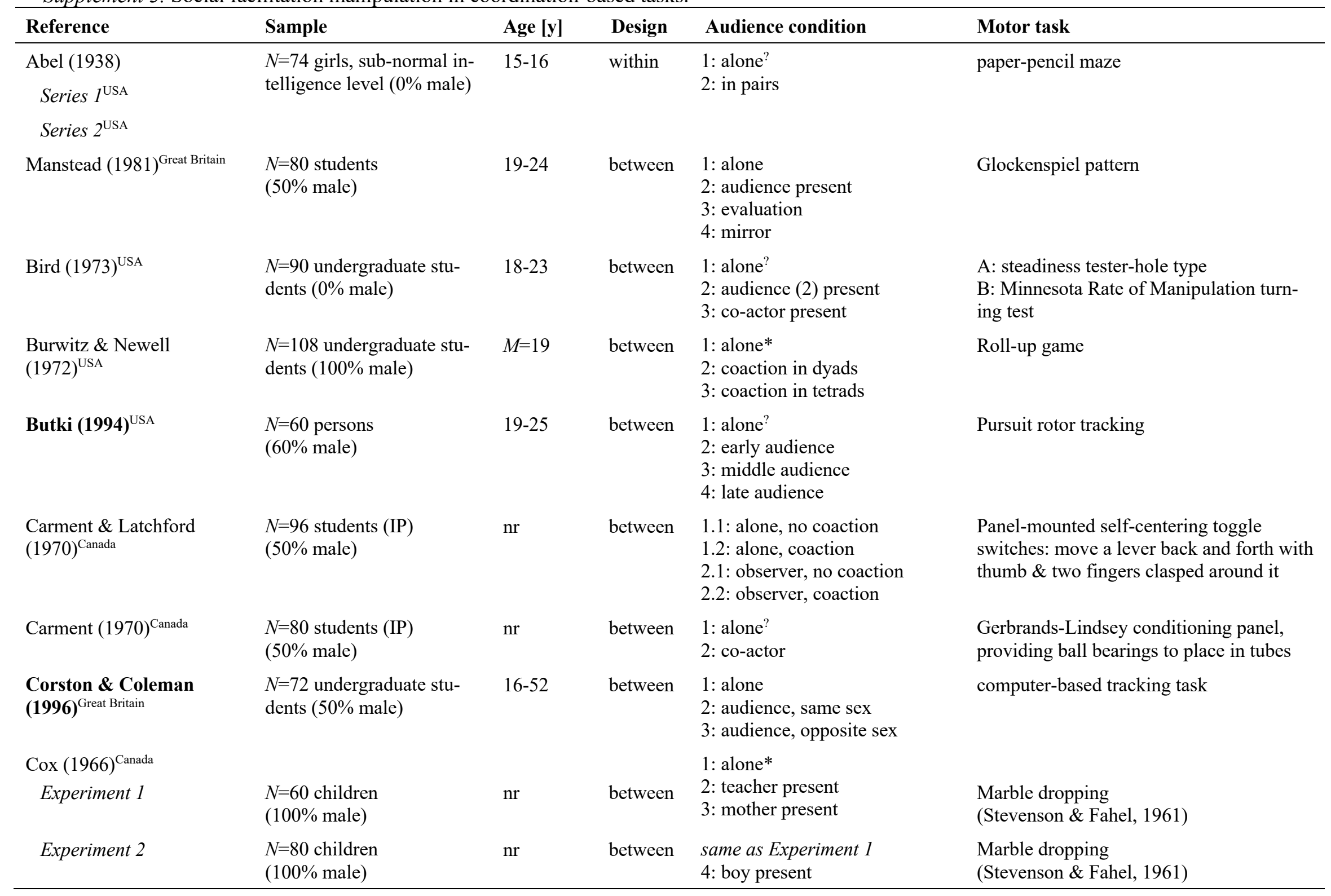




\begin{tabular}{|c|c|c|c|c|c|}
\hline Reference & Sample & Age $[y]$ & Design & Audience condition & Motor task \\
\hline Experiment 3 & $\begin{array}{l}N=60 \text { children } \\
(100 \% \text { male })\end{array}$ & $\mathrm{nr}$ & between & $\begin{array}{l}\text { 1: alone* } \\
\text { 2: teacher present } \\
\text { 3: unknown female present }\end{array}$ & $\begin{array}{l}\text { Marble dropping } \\
\text { (Stevenson \& Fahel, 1961) }\end{array}$ \\
\hline $\begin{array}{l}\text { Cox }(1968)^{\text {Canada }} \\
\text { Experiment } 1\end{array}$ & $\begin{array}{l}N=60 \text { children } \\
(100 \% \text { male })\end{array}$ & $\mathrm{nr}$ & between & $\begin{array}{l}\text { 1: alone* } \\
\text { 2: teacher present } \\
\text { 3: father present }\end{array}$ & $\begin{array}{l}\text { Marble dropping } \\
\text { (Stevenson \& Fahel, 1961) }\end{array}$ \\
\hline Experiment 2 & $\begin{array}{l}N=80 \text { children } \\
(100 \% \text { male })\end{array}$ & $\mathrm{nr}$ & between & $\begin{array}{l}\text { same es Experiment } 1 \\
\text { 4: classmate present }\end{array}$ & $\begin{array}{l}\text { Marble dropping } \\
\text { (Stevenson \& Fahel, 1961) }\end{array}$ \\
\hline Experiment 3 & $\begin{array}{l}N=60 \text { children } \\
(100 \% \text { male })\end{array}$ & $\mathrm{nr}$ & between & $\begin{array}{l}\text { 1: alone* } \\
\text { 2: teacher present } \\
\text { 3: unknown male present }\end{array}$ & $\begin{array}{l}\text { Marble dropping } \\
\text { (Stevenson \& Fahel, 1961) }\end{array}$ \\
\hline Crabbe (1973) ${ }^{\mathrm{USA}, \text { unpublished }}$ & $N=240$ children $(\mathrm{nr})$ & $\mathrm{nr}$ & between & $\begin{array}{l}\text { 1: alone } \\
\text { 2: experimenter as audience }\end{array}$ & Stabilometer balancing task \\
\hline Fouts $(1980)^{\text {Canada }}$ & $N=48(50 \%$ male $)$ & $10-11$ & within & $\begin{array}{l}\text { 1: alone? } \\
\text { 2: audience present }\end{array}$ & pressing buttons in a sequence \\
\hline $\begin{array}{l}\text { Gates }(\mathbf{1 9 2 4})^{\mathrm{USA}} \\
\text { First condition }\end{array}$ & $\begin{array}{l}N=62 \text { college students } \\
(0 \% \text { male })\end{array}$ & $\mathrm{nr}$ & between & $\begin{array}{l}\text { 1: alone* } \\
\text { 2: small audience (4-6) }\end{array}$ & Coordination (Three Hole) Test \\
\hline Second condition & $\begin{array}{l}N=62 \text { college students } \\
(0 \% \text { male })\end{array}$ & $\mathrm{nr}$ & between & $\begin{array}{l}\text { 1: alone* } \\
\text { 2: large audience }(27-37)\end{array}$ & \\
\hline Griffith et al. (1989) Australia & $\begin{array}{l}N=64 \text { right-handed under- } \\
\text { graduates (nr) }\end{array}$ & $\mathrm{nr}$ & between & $\begin{array}{l}\text { 1: alone* } \\
\text { 2: co-actor }\end{array}$ & $\begin{array}{l}\text { Happy Man Maze Game (computer): sim- } \\
\text { ple \& difficult maze conditions }\end{array}$ \\
\hline Guerin $(1986)^{\mathrm{USA}}$ & $\begin{array}{l}N=39 \text { undergraduate stu- } \\
\text { dents (nr) }\end{array}$ & $\mathrm{nr}$ & between & $\begin{array}{l}\text { 1: alone } \\
\text { 2: a mirror to distract } \\
\text { 3: confederate (no evaluation) }\end{array}$ & $\begin{array}{l}\text { Pursuit rotor tracking } \\
(30 \mathrm{rpm})\end{array}$ \\
\hline $\begin{array}{l}\text { Haas \& Roberts }(1975)^{\mathrm{USA}} \\
\text { learning } \\
\text { performing }\end{array}$ & $\begin{array}{l}N=45 \text { right-handed under- } \\
\text { graduate students }(0 \% \\
\text { male) }\end{array}$ & $\mathrm{nr}$ & within & $\begin{array}{l}\text { 1: alone } \\
\text { 2: blindfolded audience } \\
\text { 3: evaluative audience }\end{array}$ & computer-based tracking task \\
\hline Hall \& Bunker (1979) ${ }^{\mathrm{USA}}$ & $\begin{array}{l}N=128 \text { students (IP \& PE) } \\
(\mathrm{nr})\end{array}$ & $\mathrm{nr}$ & between & $\begin{array}{l}\text { 1: alone } \\
\text { 2: co-actor present }\end{array}$ & Roll-up game (Rotter, 1966) \\
\hline Hollifield (1982) ${ }^{\text {USA }}$ & $\begin{array}{l}N=80 \text { children } \\
(100 \% \text { male })\end{array}$ & $M=9.5$ & between & $\begin{array}{l}\text { 1: alone } \\
\text { 2: evaluative audience }\end{array}$ & $\begin{array}{l}\text { Pursuit rotor tracking (no information on } \\
\text { speed) }\end{array}$ \\
\hline
\end{tabular}




\begin{tabular}{|c|c|c|c|c|c|}
\hline Reference & Sample & Age $[y]$ & Design & Audience condition & Motor task \\
\hline $\begin{array}{l}\text { Hutchinson \& Cotton } \\
(1973)^{\text {USA }}\end{array}$ & $\begin{array}{l}N=144 \text { freshmen }(\mathrm{PE}) \\
(0 \% \text { male })\end{array}$ & $\mathrm{nr}$ & within & $\begin{array}{l}\text { 1: alone* } \\
\text { 2: unknown male audience } \\
\text { 3: unknown female audience }\end{array}$ & $\begin{array}{l}\text { ball-throwing skill (variation of (McCraw, } \\
\text { 1955), multiple conditions }\end{array}$ \\
\hline $\begin{array}{l}\text { Innes \& Gordon } \\
(1985)^{\text {Australia }}\end{array}$ & $\begin{array}{l}N=60 \text { students } \\
(0 \% \text { male })\end{array}$ & $\mathrm{nr}$ & between & $\begin{array}{l}\text { 1: alone? } \\
\text { 2: mirror } \\
\text { 3: audience (1) present }\end{array}$ & wire loop game (Biedny, 1969) \\
\hline Johnson $(1974)^{\text {USA, unpublished }}$ & $\begin{array}{l}N=72 \text { students } \\
(0 \% \text { male })\end{array}$ & $M=19.4$ & between & $\begin{array}{l}\text { 1: alone* } \\
\text { 2: observing audience } \\
\text { 3: evaluating audience }\end{array}$ & Stabilometer balancing task \\
\hline $\begin{array}{l}\text { Kenyon \& Loy }(1966)^{\mathrm{USA}} \\
\text { Task } 1\end{array}$ & $\begin{array}{l}N=47 \text { undergraduates } \\
(100 \% \text { male })\end{array}$ & $\mathrm{nr}$ & between & $\begin{array}{l}\text { 1: alone* } \\
\text { 2: small audience } \\
\text { 3: prestigious audience }\end{array}$ & $\begin{array}{l}\text { Manual dexterity: insert } 60 \text { blocks into } \\
\text { holes as quickly as possible }\end{array}$ \\
\hline Task 2 & & & & 4: female audience & $\begin{array}{l}\text { Manual dexterity: turn } 60 \text { blocks, then in- } \\
\text { sert into holes as quickly as possible }\end{array}$ \\
\hline Kieffer $(1977)^{\text {USA }}$ & $\begin{array}{l}N=181 \text { boys }(\text { grade } 6) \\
(100 \% \text { male })\end{array}$ & $\mathrm{nr}$ & between & $\begin{array}{l}\text { 1: alone } \\
\text { 2: audience (1) present }\end{array}$ & $\begin{array}{l}\text { Pursuit rotor tracking (no information on } \\
\text { speed - two different conditions) }\end{array}$ \\
\hline Kozar $(1973)^{\text {USA }}$ & $\begin{array}{l}N=150 \text { students }(\mathrm{PE}) \\
(100 \% \text { male })\end{array}$ & $\mathrm{nr}$ & between & $\begin{array}{l}\text { 1: alone } \\
\text { 2: supportive audience } \\
\text { 3: non-supportive audience }\end{array}$ & Stabilometer balancing task \\
\hline $\begin{array}{l}\text { Landers \& Landers } \\
(1973)^{\text {USA }}\end{array}$ & $\begin{array}{l}N=100 \text { grade } 5 \& 6 \text { stu- } \\
\text { dents }(0 \% \text { male })\end{array}$ & $10-12$ & between & $\begin{array}{l}\text { 1: alone* } \\
\text { 2: model audience }\end{array}$ & $\begin{array}{l}\text { free standing balance ladder (Bachman, } \\
\text { 1961) }\end{array}$ \\
\hline Donna Landers $(1975)^{\mathrm{USA}}$ & $\begin{array}{l}N=180 \text { middle school stu- } \\
\text { dents }(0 \% \text { male })\end{array}$ & $11-13$ & between & $\begin{array}{l}\text { 1: alone* } \\
\text { 2: experimenter present } \\
\text { 3: model audience } \\
\text { 4: unfamiliar audience }\end{array}$ & $\begin{array}{l}\text { free standing balance ladder (Bachman, } \\
\text { 1961) }\end{array}$ \\
\hline $\begin{array}{l}\text { Landers et al. }(1977)^{\text {USA, un- }} \\
\text { published }\end{array}$ & $N=134(\mathrm{nr})$ & $\mathrm{nr}$ & between & $\begin{array}{l}\text { 1: alone } \\
\text { 2: observer present } \\
\text { 3: co-actor present }\end{array}$ & Maze task (Hunt \& Hillery, 1973) \\
\hline Lau et al. (2019) Germany & $\begin{array}{l}N=70 \text { students } \\
(36 \% \text { male })\end{array}$ & 23.34 & within & $\begin{array}{l}\text { 1: alone* } \\
\text { 2: observer present }\end{array}$ & $\begin{array}{l}\text { Nintendo Wii Balanceboard: } \\
\text { "bullet maze" }\end{array}$ \\
\hline Livingston et al. (1974) ${ }^{\mathrm{USA}}$ & $\begin{array}{l}N=189 \text { subjects } \\
(0 \% \text { male })\end{array}$ & $15-16$ & between & $\begin{array}{l}\text { 1: alone* } \\
\text { 2: heterogeneous co-actor } \\
\text { 3: homogeneous co-actor }\end{array}$ & $\begin{array}{l}\text { free standing balance ladder (Bachman, } \\
\text { 1961) }\end{array}$ \\
\hline
\end{tabular}




\begin{tabular}{|c|c|c|c|c|c|}
\hline Reference & Sample & Age [y] & Design & Audience condition & Motor task \\
\hline $\begin{array}{l}\text { Lombardo \& Catalano } \\
(1975)^{\text {USA }}\end{array}$ & $\begin{array}{l}N=72 \text { students (IP) } \\
(42 \% \text { male) }\end{array}$ & $17-22$ & between & $\begin{array}{l}\text { 1: alone? } \\
\text { 2: normal audience } \\
\text { 3: expert audience }\end{array}$ & $\begin{array}{l}\text { Pursuit rotor tracking } \\
(60 \mathrm{rpm})\end{array}$ \\
\hline $\begin{array}{l}\text { Lombardo \& Catalano } \\
(1978)^{\text {USA }}\end{array}$ & $N=61$ students (IP) & $17-22$ & between & $\begin{array}{l}\text { 1: alone* } \\
\text { 2: audience present }\end{array}$ & $\begin{array}{l}\text { Pursuit rotor tracking } \\
(60 \mathrm{rpm})\end{array}$ \\
\hline $\begin{array}{l}\text { MacCracken \& Stadulis } \\
(1985)^{\mathrm{USA}}\end{array}$ & $N=120$ young children $(\mathrm{nr})$ & $M=6$ & within & $\begin{array}{l}\text { 1: alone* } \\
\text { 2: coaction }(2) \text { situation } \\
\text { 3: audience }(5) \text { present }\end{array}$ & $\begin{array}{l}\text { Balancing tasks: beam walking \& line } \\
\text { walking }\end{array}$ \\
\hline Markus $(1978)^{\text {USA }}$ & $\begin{array}{l}N=45 \text { undergraduate stu- } \\
\text { dents (IP) } \\
(100 \% \text { male })\end{array}$ & $\mathrm{nr}$ & between & $\begin{array}{l}\text { 1: alone } \\
\text { 2: attentive audience } \\
\text { 3: incidental audience }\end{array}$ & $\begin{array}{l}\text { dressing into familiar and unfamiliar } \\
\text { clothing }\end{array}$ \\
\hline Martens (1969a) ${ }^{\mathrm{USA}}$ & $\begin{array}{l}N=96 \text { undergraduate stu- } \\
\text { dents }(100 \% \text { male })\end{array}$ & $\mathrm{nr}$ & between & $\begin{array}{l}\text { 1.1: learning alone } \\
\text { 1.2: learning with audience }(10) \\
\text { 2.1: performing alone } \\
\text { 2.2: performing with audience }\end{array}$ & coincident timer \\
\hline Martens $(1969 b)^{\mathrm{USA}}$ & $\begin{array}{l}N=48 \text { undergraduate stu- } \\
\text { dents (nr) }\end{array}$ & $\mathrm{nr}$ & between & $\begin{array}{l}\text { 1: learning alone } \\
\text { 2: learning with audience (10) }\end{array}$ & coincident timer \\
\hline Martens $(1969 c)^{\text {USA }}$ & $\begin{array}{l}N=96 \text { undergraduate stu- } \\
\text { dents }(100 \% \text { male })\end{array}$ & $18-24$ & between & $\begin{array}{l}\text { 1: learning alone* } \\
\text { 2: learning with audience }(10)\end{array}$ & coincident timer \\
\hline $\begin{array}{l}\text { Martens \& Landers } \\
(1972)^{\text {USA }}\end{array}$ & $\begin{array}{l}N=132 \text { undergraduate stu- } \\
\text { dents }(\mathrm{PE}) \\
(100 \% \text { male })\end{array}$ & $\mathrm{nr}$ & between & $\begin{array}{l}\text { 1: alone } \\
\text { 2: coaction in dyads } \\
\text { 3: coaction in triads } \\
\text { 4: coaction in tetrads }\end{array}$ & Roll-up game \\
\hline $\begin{array}{l}\text { Maxwell et al. (2008) } \\
\text { Britain }\end{array}$ & $\begin{array}{l}N=28 \text { students } \\
(57 \% \text { male })\end{array}$ & $\begin{array}{l}21-37 \\
(M=24.78)\end{array}$ & within & $\begin{array}{l}\text { 1: alone } \\
\text { 2: evaluating passenger }\end{array}$ & driving simulation \\
\hline $\begin{array}{l}\text { McCullagh \& Landers } \\
(1976)^{\mathrm{USA}}\end{array}$ & $\begin{array}{l}N=96 \text { right-handed under- } \\
\text { graduates }(\mathrm{PE}) \\
(100 \% \text { male })\end{array}$ & $\mathrm{nr}$ & between & $\begin{array}{l}\text { 1: alone* } \\
\text { 2: audience (1) present ... } \\
\text { 6: audience (5) present }\end{array}$ & $\begin{array}{l}\text { Ball-rolling game (cf. (Harney \& Parker, } \\
\text { 1972), \& press buttons in sequence as } \\
\text { quickly as possible }\end{array}$ \\
\hline F. Miller et al. (1979) $)^{\mathrm{USA}}$ & $\begin{array}{l}N=50 \text { undergraduate stu- } \\
\text { dents } \\
(0 \% \text { male })\end{array}$ & $\mathrm{nr}$ & between & $\begin{array}{l}\text { 1: alone } \\
\text { 2: mere-presence audience } \\
\text { 3: evaluating audience }\end{array}$ & $\begin{array}{l}\text { Pursuit rotor tracking } \\
\text { (simple: } 30 \mathrm{rpm} \& \text { difficult: } 60 \mathrm{rpm} \text { ) }\end{array}$ \\
\hline Q.L. Miller (1989) ${ }^{\mathrm{USA}}$ & $\begin{array}{l}N=48 \text { subjects } \\
(51 \% \text { male })\end{array}$ & $M=20.5$ & between & $\begin{array}{l}\text { 1: alone } \\
\text { 2: audience present }\end{array}$ & fine motor manual dexterity skill \\
\hline
\end{tabular}




\begin{tabular}{|c|c|c|c|c|c|}
\hline Reference & Sample & Age $[y]$ & Design & Audience condition & Motor task \\
\hline Miyamoto (1979) ${ }^{\text {Japan }}$ & $\begin{array}{l}N=60 \text { students } \\
(0 \% \text { male })\end{array}$ & $\mathrm{nr}$ & between & $\begin{array}{l}\text { 1: alone* } \\
\text { 2: audience present }\end{array}$ & $\begin{array}{l}\text { Maze task: simple \& complex maze condi- } \\
\text { tions }\end{array}$ \\
\hline J. F. Murray (1983) $)^{\text {USA }}$ & $N=84$ males $\&$ females $(\mathrm{nr})$ & $\mathrm{nr}$ & between & $\begin{array}{l}\text { 1: alone } \\
\text { 2: audience present }\end{array}$ & $\begin{array}{l}\text { Stabilometer balancing task (cf. Murray, } \\
\text { 1982) }\end{array}$ \\
\hline $\begin{array}{l}\text { Pessin \& Husband } \\
(\mathbf{1 9 3 3})^{\mathrm{USA}}\end{array}$ & $\begin{array}{l}N=90 \text { students: experi- } \\
\text { mental psychology (nr) }\end{array}$ & $\mathrm{nr}$ & between & $\begin{array}{l}\text { 1: blindfolded alone* } \\
\text { 2: blindfolded, } 2 \text { spectators } \\
\text { 3: not blindfl., } 2 \text { spectators }\end{array}$ & Maze task (Warden, 1924) \\
\hline Rajecki et al. (1977) $)^{\text {USA }}$ & $\begin{array}{l}N=60 \text { students }(\text { IP }) \\
(0 \% \text { male })\end{array}$ & $\mathrm{nr}$ & between & $\begin{array}{l}\text { 1: alone } \\
\text { 2: audience; } 3 \text { : blind audience } \\
\text { 4: mannikin; 5: blind mannikin; } \\
\text { 6: mirror }\end{array}$ & Automatic tally maze \\
\hline Sasfy \& Okun (1974) & $\begin{array}{l}N=96 \text { students }(\mathrm{IP}) \\
(100 \% \text { male })\end{array}$ & $\mathrm{nr}$ & between & $\begin{array}{l}\text { 1: alone } \\
\text { 2: expert audience } \\
\text { 3: non-expert audience }\end{array}$ & Roll-up game \\
\hline Sawyer \& Noel $(2000)^{\text {USA }}$ & $\begin{array}{l}N=64 \text { high school students } \\
(52 \% \text { male })\end{array}$ & $15-18$ & between & $\begin{array}{l}\text { 1: alone* } \\
\text { 2: audience present }\end{array}$ & Pursuit rotor tracking \\
\hline $\begin{array}{l}\text { Shaver \& Liebling (1976) } \\
\text { Experiment } 1^{\mathrm{USA}}\end{array}$ & $\begin{array}{l}N=30 \text { undergraduate stu- } \\
\text { dents (IP) } \\
(100 \% \text { male })\end{array}$ & $\mathrm{nr}$ & between & $\begin{array}{l}\text { 1: alone } \\
\text { 2: observed whilst instructions } \\
\text { 3: observed after instructions }\end{array}$ & Maze task (Hunt \& Hillery, 1973) \\
\hline Experiment $2^{\mathrm{USA}}$ & $\begin{array}{l}N=64 \text { undergraduate stu- } \\
\text { dents (IP) } \\
(100 \% \text { male })\end{array}$ & $\mathrm{nr}$ & between & $\begin{array}{l}\text { 1: low fear - alone } \\
\text { 2: high fear - alone } \\
\text { 3: high fear - calm observer } \\
\text { 4: worried observer }\end{array}$ & Maze task (Hunt \& Hillery, 1973) \\
\hline $\begin{array}{l}\text { Simensky (1991) } \\
\text { hed }\end{array}$ & $\begin{array}{l}N=80 \text { students } \\
(100 \% \text { male })\end{array}$ & $\mathrm{nr}$ & between & $\begin{array}{l}\text { 1: alone? } \\
\text { 2: audience present }\end{array}$ & $\begin{array}{l}\text { free standing balance ladder (Bachman, } \\
\text { 1961) }\end{array}$ \\
\hline Singer (1965) $)^{\mathrm{USA}}$ & $\begin{array}{l}n=15 \text { athletes } \& n=16 \text { non- } \\
\text { athletes/PE majors (nr) }\end{array}$ & $\mathrm{nr}$ & within & $\begin{array}{l}\text { 1: alone } \\
\text { 2: audience present }\end{array}$ & $\begin{array}{l}\text { Stabilometer balancing task, adap. from } \\
\text { (Bachman, 1961) }\end{array}$ \\
\hline Singer $(1970)^{\mathrm{USA}}$ & $\begin{array}{l}N=40 \text { (under-) graduate } \\
\text { students (PE; 80\% male) }\end{array}$ & $\mathrm{nr}$ & within & $\begin{array}{l}\text { 1: alone* } \\
\text { 2: audience present }\end{array}$ & mirror-tracing task \\
\hline Travis (1925) ${ }^{\mathrm{USA}}$ & $\begin{array}{l}n=20 \text { freshmen, } \\
n=1 \text { sophomore, } n=1 \text { jun- } \\
\text { ior }(91 \% \text { male })\end{array}$ & $\mathrm{nr}$ & within & $\begin{array}{l}\text { 1: alone* } \\
\text { 2: audience present }\end{array}$ & Pursuit rotor tracking (Koerth, 1922) \\
\hline
\end{tabular}




\begin{tabular}{|c|c|c|c|c|c|}
\hline Reference & Sample & Age [y] & Design & Audience condition & Motor task \\
\hline Wankel $(1972)^{\text {Canada }}$ & $\begin{array}{l}N=160 \text { right-handed stu- } \\
\text { dents (grade } 7 \& 8 ; 100 \% \\
\text { male) }\end{array}$ & $\mathrm{nr}$ & between & $\begin{array}{l}\text { 1.1: alone* } \\
\text { 1.2: co-actor present } \\
\text { 2.1: alone } \\
\text { 2.2: audience present }\end{array}$ & $\begin{array}{l}\text { Press buttons in sequence as quickly as } \\
\text { possible }\end{array}$ \\
\hline Wankel $(1975)^{\text {Canada }}$ & $\begin{array}{l}N=36 \text { boys from grade } 7 \& \\
8(100 \% \text { male })\end{array}$ & $\mathrm{nr}$ & between & $\begin{array}{l}\text { 1: alone* } \\
\text { 2: audience present }\end{array}$ & $\begin{array}{l}\text { Stabilometer balancing task (Singer, 1968; } \\
\text { Wankel, 1969) }\end{array}$ \\
\hline Wankel $(1977)^{\text {Canada }}$ & $\begin{array}{l}N=60 \text { subjects } \\
(0 \% \text { male })\end{array}$ & $\mathrm{nr}$ & between & $\begin{array}{l}1: \text { alone } \\
2: 2 \text { observers } \\
3: 5-6 \text { observers }\end{array}$ & $\begin{array}{l}\text { Pursuit rotor tracking } \\
(60 \mathrm{rpm})\end{array}$ \\
\hline White (1991) ${ }^{\mathrm{USA}}$ & $\begin{array}{l}N=108 \text { college-age sub- } \\
\text { jects }(\mathrm{nr})\end{array}$ & $\mathrm{nr}$ & between & $\begin{array}{l}\text { 1: non-competitive situation? } \\
\text { 2: competitive situation } \\
3: \text { cooperative situation }\end{array}$ & $\begin{array}{l}\text { Pursuit rotor tracking } \\
(60 \mathrm{rpm})\end{array}$ \\
\hline
\end{tabular}

$\mathrm{PE}=$ physical education; $\mathrm{IP}=$ introductory psychology course; $\mathrm{nr}=$ not reported;

*=experimenter present in alone condition, ${ }^{=}=$no information on presence of experimenter

Supplement 4. Social-facilitation manipulation in condition-based tasks.

\begin{tabular}{|c|c|c|c|c|c|}
\hline Reference & Sample & Age $[y]$ & Design & Audience condition & Motor task \\
\hline Ben-Ezra et al. (1986) ${ }^{\mathrm{USA}}$ & $\begin{array}{l}N=13 \text { visually impaired } \\
\text { men }(100 \% \text { male })\end{array}$ & $18-34$ & within & $\begin{array}{l}\text { 1: alone? } \\
\text { 2: co-actor present }\end{array}$ & $60 \mathrm{~m}$ sprint dash \\
\hline $\begin{array}{l}\text { Beckmann \& Strang } \\
(1992)^{\text {GER }}\end{array}$ & $\begin{array}{l}N=80 \text { students }(100 \% \\
\text { male })\end{array}$ & $M d n=23$ & within & $\begin{array}{l}\text { 1: alone* } \\
\text { 2: professor and staff member }\end{array}$ & Leg press, maximal weight \\
\hline $\begin{array}{l}\text { Bowman \& Dunn } \\
(1982)^{\text {USA }}\end{array}$ & $\begin{array}{l}N=30 \text { educable mentally } \\
\text { retarded children } \\
(67 \% \text { male })\end{array}$ & $M=10.42$ & between & $\begin{array}{l}\text { 1: alone* } \\
\text { 2: audience present }\end{array}$ & $\begin{array}{l}\text { 1: sit-ups for } 60 \mathrm{~s} \\
\text { 2: Shuttle Run Test } \\
\text { 3: standing broad jump }\end{array}$ \\
\hline Chevrette (1968) $)^{\mathrm{USA}}$ & $\begin{array}{l}N=59 \text { children } \\
(59 \% \text { male })\end{array}$ & $\mathrm{nr}$ & within & $\begin{array}{l}\text { 1: alone* } \\
\text { 2: same-sex audience } \\
\text { 3: opposite-sex audience } \\
\text { 4: mixed-sex audience }\end{array}$ & $\begin{array}{l}\text { 1: vertical hang from the horizontal bar } \\
\text { 2: grip strength (dynamometer) } \\
\text { 3: Shuttle Run Test }\end{array}$ \\
\hline $\begin{array}{l}\text { EI Baden (1984) } \\
\text { hed }\end{array}$ & $\begin{array}{l}N=312 \text { undergraduate } \mathrm{PE} \\
\text { students ( } 50 \% \text { male })\end{array}$ & $18-29$ & between & $\begin{array}{l}\text { 1: alone? } \\
\text { 2: passive audience } \\
\text { 3: } 3 \text { co-actors present }\end{array}$ & $\begin{array}{l}\text { 1: } 12 \text { min run-and-walk test } \\
\text { 2: sit-ups for } 60 \mathrm{~s} \\
3: \text { sit and reach }\end{array}$ \\
\hline
\end{tabular}




\begin{tabular}{|c|c|c|c|c|c|}
\hline Reference & Sample & Age [y] & Design & Audience condition & Motor task \\
\hline Feltz et al. (2011) ${ }^{\mathrm{USA}}$ & $\begin{array}{l}N=181 \text { college students (IP } \\
\& \text { kinesiology) } \\
(48 \% \text { male })\end{array}$ & $\begin{array}{l}M=20.10 \\
(S D=1.75)\end{array}$ & between & $\begin{array}{l}\text { 1: alone* } \\
\text { 2: coactive } \\
\text { 3: additive } \\
\text { 4: conjunctive }\end{array}$ & $\begin{array}{l}\text { five isometric exercises: } \\
\text { front plank, side plank (left), one leg plank } \\
\text { (left), side plank (right), one leg plank } \\
\text { (right) }\end{array}$ \\
\hline $\begin{array}{l}\text { Kamal (1980) } \\
\text { hed }\end{array}$ & $\begin{array}{l}N=80 \text { athletes } \\
(100 \% \text { male })\end{array}$ & $\mathrm{nr}$ & within & $\begin{array}{l}\text { 1: alone? } \\
\text { 2: non-competitive co-actor } \\
\text { 3: competitive co-actor }\end{array}$ & swimming $2 \times 25 \mathrm{~m}$ laps \\
\hline $\begin{array}{l}\text { Kenyon \& Loy }(1966)^{\mathrm{USA}} \\
\text { Task } 3\end{array}$ & $\begin{array}{l}N=47 \text { undergraduates } \\
(100 \% \text { male })\end{array}$ & $\mathrm{nr}$ & between & $\begin{array}{l}\text { 1: alone* } \\
\text { 2: small audience } \\
\text { 3: prestigious audience }\end{array}$ & Max wrist strength (dynamometer) \\
\hline Task 4 & & & & 4: female audience & $\begin{array}{l}1 / 2 \text { max wrist strength (dynamometer, hold } \\
\text { for as long as possible }\end{array}$ \\
\hline $\begin{array}{l}\text { Martens \& Landers } \\
(1969)^{\text {USA }}\end{array}$ & $\begin{array}{l}n=60 \text { young boys, } n=60 \\
\text { older boys \& } n=60 \text { college } \\
\text { men } \\
(100 \% \text { male })\end{array}$ & $\begin{array}{l}m=7.92 \\
m=13.67 \\
m=19.17\end{array}$ & between & $\begin{array}{l}\text { 1: alone* } \\
\text { 2: coaction in dyads } \\
\text { 3: coaction in quadrats }\end{array}$ & horizontal leg extension \\
\hline $\begin{array}{l}\text { E. Murray et al. } \\
(2016)^{\text {Australia }}\end{array}$ & $\begin{array}{l}N=60 \text { students }(\mathrm{IP}) \\
(0 \% \text { male })\end{array}$ & $\begin{array}{l}M=20.20 \\
(S D=2.73)\end{array}$ & between & $\begin{array}{l}\text { 1: no virtual reality? } \\
\text { 2: alone in virtual reality } \\
\text { 3: virtual companion }\end{array}$ & Virtual reality rowing \\
\hline Piché \& Sachs $(1982)^{\text {Canada }}$ & $\begin{array}{l}N=24 \text { students } \\
(100 \% \text { male })\end{array}$ & $\mathrm{nr}$ & between & $\begin{array}{l}\text { 1: alone* } \\
\text { 2: unfamiliar co-actor } \\
\text { 3: familiar co-actor }\end{array}$ & exert pressure on a $6 \mathrm{ft}$ pole \\
\hline Selan (1986) ${ }^{\mathrm{USA}, \text { unpublished }}$ & $\begin{array}{l}N=193 \text { students } \\
(100 \% \text { male })\end{array}$ & $\mathrm{nr}$ & within & $\begin{array}{l}\text { 1: alone } \\
\text { 2: equally skilled audience } \\
\text { 3: superior skilled audience }\end{array}$ & Box/weightlifting \\
\hline $\begin{array}{l}\text { Sheridan et al. (2019) } \\
\text { Britain }\end{array}$ & $\begin{array}{l}N=12 \text { recreational athletes } \\
(100 \% \text { male })\end{array}$ & $\begin{array}{l}M=21.3 \\
(S D=0.8)\end{array}$ & within & $\begin{array}{l}\text { 1: spotter hidden* } \\
\text { 2: spotter openly present }\end{array}$ & $\begin{array}{l}\text { bench press performance at } 60 \% \text { of sub- } \\
\text { ject's } 1 \text { RM }\end{array}$ \\
\hline $\begin{array}{l}\text { Strube et al. (1981) } \\
\text { Experiment } 1^{\mathrm{USA}}\end{array}$ & $\begin{array}{l}N=120 \text { joggers (indoor } \\
\text { track) }(50 \% \text { male })\end{array}$ & $19-30$ & unclear & $\begin{array}{l}\text { 1: alone } \\
\text { 2: inattentive audience (1) } \\
\text { 3: attentive audience (2) }\end{array}$ & running (17.98m stretch) \\
\hline Experiment $2^{\mathrm{USA}}$ & $\begin{array}{l}N=36 \text { joggers (indoor } \\
\text { track) }(50 \% \text { male })\end{array}$ & $19-30$ & unclear & $\begin{array}{l}\text { 1: alone } \\
\text { 2: inattentive audience (1) } \\
\text { 3: attentive audience }(2)\end{array}$ & running (17.98m stretch) \\
\hline $\begin{array}{l}\text { Thielemier \& Church } \\
\text { (2014) } \\
\text { USA, unpublished }\end{array}$ & $\begin{array}{l}N=17 \text { athletes } \\
(100 \% \text { male })\end{array}$ & $M=21.3$ & within & $\begin{array}{l}\text { 1: alone } \\
2: \text { audience }\end{array}$ & running (12 minutes on treadmill) \\
\hline
\end{tabular}




\begin{tabular}{|c|c|c|c|c|c|}
\hline Reference & Sample & Age $[y]$ & Design & Audience condition & Motor task \\
\hline Weinstein et al. $(\mathbf{1 9 8 7})^{\text {USA }}$ & $\begin{array}{l}N=14 \text { baseball pitchers } \\
(100 \% \text { male })\end{array}$ & $M=20.36$ & within & $\begin{array}{l}\text { 1: experimenter hidden } \\
\text { 2: experimenter visible }\end{array}$ & Baseball throw (fastballs) \\
\hline $\begin{array}{l}\text { Worringham \& Messick } \\
(\mathbf{1 9 8 3})^{\mathrm{USA}}\end{array}$ & $\begin{array}{l}N=36 \text { joggers } \\
(50 \% \text { male })\end{array}$ & $\mathrm{nr}$ & between & $\begin{array}{l}\text { 1: alone } \\
\text { 2: attentive audience } \\
\text { 3: inattentive audience }\end{array}$ & running (45 yards) \\
\hline
\end{tabular}

$\mathrm{PE}=$ physical education; $\mathrm{IP}=$ introductory psychology course; $\mathrm{nr}=$ not reported;

$*=$ experimenter present in alone condition, $?=$ no information on presence of experimenter

Supplement 5. Social-facilitation manipulation in mixed motor tasks.

\begin{tabular}{|c|c|c|c|c|}
\hline Reference & Sample & Age [y] & Audience condition & Motor task \\
\hline Bell \& Yee $(1989)^{\text {USA }}$ & $\begin{array}{l}N=33 \text { karate students } \\
(76 \% \text { male })\end{array}$ & $\begin{array}{l}13-38 \\
(M=23.85)\end{array}$ & $\begin{array}{l}\text { within } \\
\text { 1: alone* } \\
\text { 2: audience present }\end{array}$ & Karate kicks \\
\hline Dube \& Tatz (1991) $)^{\mathrm{USA}}$ & $\begin{array}{l}N=32 \text { tennis campers } \\
(66 \% \text { male })\end{array}$ & $9-14$ & $\begin{array}{l}\text { within } \\
\text { 1: alone* } \\
\text { 2: audience present }\end{array}$ & $\begin{array}{l}\text { Tennis match of low- and high-skilled campers, } \\
\text { evaluated on good and bad shots by referee }\end{array}$ \\
\hline Forgas et al. (1980) $)^{\text {Australia }}$ & $\begin{array}{l}N=40 \text { squash players } \\
(100 \% \text { male })\end{array}$ & $\mathrm{nr}$ & $\begin{array}{l}\text { within } \\
\text { 1: alone } \\
\text { 2: male (2) audience } \\
\text { 3: female (2) audience }\end{array}$ & Squash match \\
\hline Geisler \& Leith (1997) ${ }^{\text {Great Britain }}$ & $\begin{array}{l}N=40 \text { soccer players } \\
(100 \% \text { male })\end{array}$ & $\begin{array}{l}19-34 \\
(M=23.8 \\
S D=3.5)\end{array}$ & $\begin{array}{l}\text { between } \\
\text { 1: alone } \\
\text { 2: audience }(5) \text { present }\end{array}$ & Penalty kicks \\
\hline Graydon \& Murphy (1995) & $\begin{array}{l}N=20 \text { students }(\mathrm{PE}) \\
(100 \% \text { male })\end{array}$ & $18-22$ & $\begin{array}{l}\text { within } \\
\text { 1: alone* } \\
\text { 2: audience present }\end{array}$ & $\begin{array}{l}\text { table tennis forehand serves (diagonally into } \\
\text { marked grid) }\end{array}$ \\
\hline Krendl et al. (2012) $)^{\text {USA }}$ & $\begin{array}{l}N=74 \text { white (under- } \\
\text { )graduate students } \\
(100 \% \text { male) }\end{array}$ & $18-30$ & $\begin{array}{l}\text { between } \\
\text { 1: alone* } \\
\text { 2: observation condition }\end{array}$ & Basketball free throws \\
\hline Navarro et al. $(2013)^{\text {Netherlands }}$ & $\begin{array}{l}N=10 \text { university footbal- } \\
\text { lers } \\
(100 \% \text { male })\end{array}$ & $\begin{array}{l}M=19.1 \\
(S D=1.9)\end{array}$ & $\begin{array}{l}\text { within } \\
\text { 1: goalkeeper absent? } \\
\text { 2: goalkeeper } \\
\text { 3: knowledgeable goalkeeper }\end{array}$ & Penalty kicks \\
\hline
\end{tabular}




\begin{tabular}{|c|c|c|c|c|}
\hline Reference & Sample & Age [y] & Audience condition & Motor task \\
\hline \multicolumn{5}{|l|}{ Paulus et al. (1972) } \\
\hline Experiment $1^{\mathrm{USA}}$ & $\begin{array}{l}N=25 \text { students (introduc- } \\
\text { tory gymnastics) } \\
(100 \% \text { male })\end{array}$ & $\mathrm{nr}$ & $\begin{array}{l}\text { between } \\
\text { 1: alone } \\
\text { 2: audience (17) present }\end{array}$ & $\begin{array}{l}\text { floor exercise routine (forward \& backward rolls, } \\
\text { Swedish fall, } 3 \text { leg circles, headstand, dive roll) }\end{array}$ \\
\hline Experiment $2^{\mathrm{USA}}$ & $\begin{array}{l}N=21 \text { students (introduc- } \\
\text { tory gymnastics) } \\
(100 \% \text { male })\end{array}$ & $\mathrm{nr}$ & $\begin{array}{l}\text { between } \\
\text { 1: alone } \\
\text { 2: audience (17) present }\end{array}$ & $\begin{array}{l}\text { floor exercise routine (forward \& backward rolls, } \\
\text { Swedish fall, } 3 \text { leg circles, headstand, dive roll) }\end{array}$ \\
\hline Paulus \& Cornelius (1974) ${ }^{\text {USA }}$ & $\begin{array}{l}N=45 \text { students (gymnas- } \\
\text { tics) } \\
(100 \% \text { male })\end{array}$ & $\mathrm{nr}$ & $\begin{array}{l}\text { between } \\
\text { 1: alone? } \\
\text { 2: no warning of } 17 \text { spectators } \\
\text { 3: warning of } 17 \text { spectators }\end{array}$ & pommel horse routine \\
\hline Welch (2005) ${ }^{\text {USA, unpublished }}$ & $\begin{array}{l}N=27 \text { children } \\
(0 \% \text { male })\end{array}$ & $18-22$ & $\begin{array}{l}\text { within } \\
\text { 1: alone* } \\
\text { 2: observer present }\end{array}$ & Basketball free throws \\
\hline
\end{tabular}

$\mathrm{PE}=$ physical education; $\mathrm{IP}=$ introductory psychology course; $\mathrm{nr}=$ not reported;

$*=$ experimenter present in alone condition, ${ }^{=}=$no information on presence of experimenter 
Supplement 6. Reason for exclusion when applying the inclusion criteria.

1. Anderson-Hanley et al. (2011): participants were asked to cycle against and outpace a competitive on-screen rider. Since social facilitation has been distinguished from rivalry (Allport, 1920; Burnham, 1910; Dashiell, 1935), this study was excluded.

2. Bird (1975): The subjects performed an accuracy task either in the presence of a same-sex or an opposite-sex audience. However, there was no alone-condition from which to derive a social facilitation effect.

3. Corbett et al. (2012): This study compared time-trial performance run alone to a simulated head-to-head competition. Since social facilitation has been distinguished from rivalry (Allport, 1920; Burnham, 1910; Dashiell, 1935), this study was excluded.

4. Douglas (1983): Douglas (1983) investigated mentally retarded adolescents which were deemed incomparable to the present sample and research question.

5. Edwards et al. (2018): This study compared the performance during exhausting exercises with external verbal encouragement to a condition where the encouraging female sat passively $5 \mathrm{~m}$ away. This latter condition can either be considered the alone condition (with experimenter present) or the social facilitation condition, however, in both cases, no social facilitation can be estimated.

6. Fantoni et al. (2016): Similar to Bird (1975), did not provide information on an alone condition. Hence, no claim about social facilitation could be made to contribute to this systematic review.

7. Geukes et al. (2012): The aim of this study was to test the influence of pressure on an accuracy performance. Therefore, a high-pressure situation with an audience of 1500-2000 spectators was created. However, additionally, a reward of up to $€ 150$ for the most accurate shooter was announced, which confounds potential social effects. Accordingly, the study was excluded.

8. Hrycaiko \& Hrycaiko (1980): In a study employing the ball roll-up task either in the presence of an audience or alone, only palmar sweating and heart rate were measured, but no performance comparison was provided.

9. Lasky (1986): Subjects performed basketball layups and foul shots either in the presence of male or female athletes or non-athletes, but never alone, which made it impossible to estimate a social facilitation effect.

10. Law et al. (2003): Table-tennis shot performance was assessed under three audience conditions: observation-only, supportive, and adversarial. In no condition was performance without an audience assessed, which made it impossible to estimate a social facilitation effect.

11. Martens and Landers (1969): Known for their work in the field of social facilitation, Martens and Landers in this study gave specific competitive information as comparison to other participants (cf. p. 3). To avoid rivalry confounding effects, the study was not included in the systematic review.

12. Mesagno et al. (2011): Similar to Geukes et al. (2012), this study provided monetary incentive in a high-pressure situation otherwise characterized as social presence condition. Hence, it was not further considered.

13. Ortín Montero et al. (2018): assessed the influence of someone else present (among others) on several objective and subjective performance evaluations (heart rate, perceived exhaustion, mood), but not on running performance.

14. Poteet and Weinberg (1980): Although reporting a social facilitation effect, Poteet and Weinberg used a competition vs no-competition experimental design on a flexed-arm hang against a confederate. To avoid effects confounded by rivalry, the study was not included in the systematic review.

15. Slevin (1971): The audience in this study, six male peer spectators, was essentially an active one, encouraging the participant throughout the task.

16. Snyder et al. (2012): The experimenter asked participants specifically to compete against different types of competitors (virtual or live). According to Dashiell (1930) or Allport (1920), any effect here would not be considered to have been caused by social facilitation. 
17. Triplett (1898): It is noteworthy that Triplett's original study, although being credited as the first experiment to measure social facilitation, fails to be included. This is due to the competitive situation in employed in the pacing partner in the experiment.

18. Walsh and Gill (2008): Subjects stood on one leg either in an inspector or a spectator condition. Neither allowed a comparison of alone vs audience comparison and hence, the study was waved.

19. Weinberg et al. (1982): manipulated both audience conditions and instructed success or failure, and afterwards assessed the subjects' attribution of their performance on a Pursuit Rotor Task, without providing information on the actual task performance. Hence, the study could not be considered for further analysis.

20. Wellner et al. (2010): In an extensive virtual-reality environment, rowers experienced audiences interspersed with silent nature-view episodes. Research expresses explicitly that social facilitation differs from social support by the involvement of the audience. In that regard, the study by Wellner et al. (2010) does not meet the requirements.

21. Whitt (1982): 96 subjects performed 20 trials on a Pursuit rotor task, in the presence of evaluative/non-evaluative expert/non-expert spectators, however, no alone condition was used to infer a social facilitation effect.

22. Whittemore (1924): rivalry between co-workers was induced through instructions and labeled social facilitation, however, in the spirit of Allport (1920) and Dashiell (1930), it was excluded from this systematic review.

To summarize, a total of 22 articles was deemed ineligible for the present analysis. An important characteristic of social facilitation is the absence of social comparison, i.e. the mere presence of others (Allport, 1920, 1924; Dashiell, 1930). Although mentioning or describing social facilitation processes, $N=9$ studies tested the theory in a competitive setting, e.g. using rewards/punishment and direct comparison to an opponent, thereby diluting the social facilitation effect (Anderson-Hanley et al., 2011; Corbett et al., 2012; Geukes et al., 2012; Martens \& Landers, 1969; Mesagno et al., 2011; Poteet \& Weinberg, 1980; Snyder et al., 2012; Triplett, 1898; Whittemore, 1924). Especially noteworthy is the mention of Triplett here, who, although being credited as the first scientist to empirically estimate social facilitation, employed a competitive situation in his experiment.

A social facilitation effect can only be gauged when a social facilitation condition without encouraging behavior is compared to a condition of performing alone (either in between-subjects or withinsubjects fashion). $N=8$ studies failed to conduct or report the latter, hence, their results were not compatible with the goal of this research (Bird, 1975; Edwards et al., 2018; Fantoni et al., 2016; Lasky, 1986; Law et al., 2003; Slevin, 1971; Walsh \& Gill, 2008; Wellner et al., 2010; Whitt, 1982). Similarly, studies $(N=3)$ that failed to report the effect the presence of an audience or co-worker had on the actual performance were excluded (Hrycaiko \& Hrycaiko, 1980; Ortín Montero et al., 2018; Weinberg et al., 1982). 


\begin{tabular}{|c|c|c|c|c|c|}
\hline & $\boldsymbol{k}$ & $d$ & $S E$ & $95 \% \mathrm{CI}$ & \\
\hline Experimenter presence & & & & & $Q(44)=317.72, p<.001, \sigma^{2}$ level $2=0.27, \sigma_{\text {level } 3}^{2}=0.20$ \\
\hline alone & 10 & 0.33 & 0.26 & {$[-0.18 ; 0.84]$} & $F(2,44)=0.78, p=.464$ \\
\hline with experimenter & 27 & 0.15 & 0.29 & {$[-0.99 ; 1.30]$} & \\
\hline Task difficulty & & & & & $Q(44)=295.22, p<.001, \sigma_{\text {level } 2}^{2}=0.20, \sigma_{\text {level } 3}^{2}=0.20$ \\
\hline simple & 21 & 0.42 & 0.25 & {$[-0.47 ; 1.31]$} & $F(2,44)=4.79, p=.013$ \\
\hline complex & 13 & -0.23 & 0.20 & {$[-0.64 ; 0.19]$} & \\
\hline Task familiarity & & & & & $Q(44)=361.18, p<.001, \sigma_{\text {level } 2}^{2}=0.26, \sigma_{\text {level } 3}^{2}=0.23$ \\
\hline familiar & 29 & 0.36 & 0.15 & {$[0.01 ; 0.72]$} & $F(2,44)=0.67, p=.517$ \\
\hline unfamiliar & 5 & -0.09 & 0.38 & {$[-1.26 ; 1.07]$} & \\
\hline Role of others & & & & & $Q(45)=316.32, p<.001, \sigma_{\text {level } 2}^{2}=0.21, \sigma_{\text {level } 3}^{2}=0.22$ \\
\hline audience & 40 & 0.17 & 0.12 & {$[-0.10 ; 0.44]$} & $F(2,45)=5.08, p=.029$ \\
\hline co-actor & 7 & 0.80 & 0.30 & {$[-0.03 ; 1.63]$} & \\
\hline Evaluation potential & & & & & $Q(42)=295.47, p<.001, \sigma^{2}$ level $2=0.21, \sigma_{\text {level } 3}^{2}=0.21$ \\
\hline observing & 17 & 0.12 & 0.34 & {$[-1.08 ; 1.32]$} & $F(4,42)=1.91 p=.126$ \\
\hline non-evaluative & 3 & 0.75 & 0.53 & {$[-0.94 ; 2.45]$} & \\
\hline evaluating & 15 & 0.14 & 0.35 & {$[-1.18 ; 1.45]$} & \\
\hline Publication status & & & & & $Q(45)=327.81, p<.001, \sigma^{2} 2_{\text {level } 2}=0.26, \sigma_{\text {level } 3}^{2}=0.21$ \\
\hline published & 37 & 0.23 & 0.33 & {$[-0.93 ; 1.38]$} & $F(1,45)=1.01, p=.368$ \\
\hline not published & 10 & 0.51 & 0.27 & {$[-0.03 ; 1.05]$} & \\
\hline
\end{tabular}

